Economia e Sociedade, Campinas, Unicamp. IE. http://dx.doi.org/10.1590/1982-3533.2020v30n1art04

\title{
Mudança estrutural e serviços intermediários: algumas evidências para o limiar do século XXI *
}

\author{
Adilson Giovanini **
}

\begin{abstract}
Resumo
Abordagens setoriais demonstram que as novas tecnologias de comunicação contribuem para a mudança no modo como as firmas organizam os seus processos produtivos, favorecendo a terceirização e o crescimento na participação de atividades de serviços intermediários. O objetivo deste estudo é avaliar o fenômeno da mudança estrutural, mediante o emprego da abordagem do subsistema (Momigliano; Siniscalco, 1982, 1986) para uma amostra composta por 43 países discriminada para o período 2000-2014. Essa abordagem integra verticalmente as atividades intermediárias que compõem cada subsistema, se mostra robusta à terceirização de atividades e possibilita a obtenção de indicadores de mudança estrutural mais confiáveis do que a abordagem setorial. Os resultados encontrados demonstram a ocorrência de um processo de reorganização produtivo caracterizado pela elevação na participação dos serviços intermediários. O estudo inova ao evidenciar a existência de tendência consistente de retração na participação dos subsistemas industriais no total de horas trabalhadas. Esse processo de desindustrialização não é explicado apenas pelo avanço do subsistema de serviços finais, mas principalmente pela crescente integração vertical observada para o subsistema de serviços intermediários. Esse subsistema registra retração na utilização de insumos oriundos dos subsistemas industriais, o que contraria alguns argumentos presentes na literatura de serviços intermediários.
\end{abstract}

Palavras-chave: Crescimento econômico, Serviços intermediários, Simbiose.

\section{Abstract \\ Structural change and intermediary services: evidence for the early 21st century}

Sectoral approaches demonstrate that new communication technologies contribute to the change in the way firms organize their production processes, favoring outsourcing and growth in the participation of intermediary service activities. The aim of this study is to evaluate the phenomenon of structural change, using the subsystem approach (Momigliano; Siniscalco, 1982 , 1986) taking a sample composed of 43 countries for the period 2000-2014. This approach vertically integrates the intermediate activities that make up each subsystem, proving to be robust to the reorganization of activities, which makes it possible to obtain more reliable indicators of structural change than the sectoral approach. The results found demonstrate the occurrence of a productive reorganization process characterized by an increase in the participation of intermediary services. They are considered innovative in that they highlight the existence of a consistent downward trend in the share of industrial subsystems in the total hours worked and in added value. This deindustrialization process is not only explained by the advancement of the final services subsystem, but mainly by the increasing vertical integration observed for the intermediate services subsystem. This subsystem registers retraction in the use of inputs from industrial subsystems, which contradicts some arguments present in the literature on intermediate services.

Keywords: Economic growth, Intermediary services, Symbiosis.

JEL L16, L22, L84, L86, O40.

\footnotetext{
* Artigo recebido em 8 de junho de 2018 e aprovado em 19 de agosto de 2020.

${ }^{* *}$ Professor de Administração Pública da Universidade do Estado de Santa Catarina (UDESC), Florianópolis, SC, Brasil. E-mail: adilson.giovanini@udesc.br. ORCiD: https://orcid.org/0000-0001-8948-1186.
} 


\section{introdução}

A literatura clássica de desenvolvimento econômico e de mudança estrutural mostra que a Indústria de transformação, doravante indústria, é capaz de promover movimentos autodeterminados de crescimento econômico. Os países que conseguem migrar para setores industriais mais sofisticados aceleram suas taxas de crescimento econômico, em detrimento dos demais países ${ }^{1}$. A adoção de políticas, sobretudo de estímulo à indústria, representa elemento central para o crescimento da renda per capita. Entretanto, evidências empíricas mais recentes mostram que os serviços intermediários também contribuem para o surgimento de inovações, promovendo mudança estrutural e aumento na produtividade industrial ${ }^{2}$. Serviços avançados fornecem conhecimentos tecnológicos demandados, principalmente, pelas atividades industriais mais sofisticadas. Essa nova literatura defende que parcela considerável das inovações que emergiram a partir da década de 1980 surgiram no setor de serviços intermediários e de sua interação com a indústria (Miles et al., 1994, 1995, 2008; Hertog, 2000; Muller, 2001; Czarnitzki et al., 2000).

Frente às evidências de que as atividades de serviços são cada vez mais utilizadas como insumo pela indústria, Francois e Reinert (1996) propuseram a divisão dessas atividades em dois grupos distintos. O termo "Serviços intermediários" é utilizado para identificar as atividades de serviços utilizadas como insumo pela indústria. Por outro lado, o termo "Serviços finais" identifica as atividades de serviços adquiridas pelos consumidores finais. Essa classificação é doravante utilizada para diferenciar as atividades de serviços mais avançadas daquelas tradicionais.

A problemática deste estudo parte dessa nova literatura internacional que defende o papel tributário das novas tecnologias de comunicação para o avanço dos serviços intermediários. Uma das implicações decorrentes da emergência das novas tecnologias de comunicação é a terceirização de atividades industriais para firmas de serviços intermediários, de modo que a utilização de uma abordagem setorial implica em viés na avaliação dos processos de mudança estrutural hodiernos, pois o aumento na participação do setor de serviços intermediários pode ser interpretado, de forma equivocada, como mudança estrutural, apesar de se constituir apenas em um ajuste na organização interna das atividades produtivas ${ }^{3}$. Por conseguinte, estudos que possuem como objetivo avaliar processos de mudança estrutural devem utilizar metodologias que sejam robustas a essa reorganização interna nas atividades produtivas (Sarra et al., 2019).

Dada essa problematização, o objetivo deste estudo é analisar o processo de mudança estrutural apresentado pelas principais economias mundiais no período 2000-2014. De forma mais precisa, se pretende isolar a mudança estrutural decorrente da reorganização nas atividades produtivas, daquela mudança estrutural genuína, decorrente da alteração na participação na demanda final. Este objetivo é alcançado mediante a aplicação da abordagem do subsistema (Sraffa, 1960; Pasinetti, 1973) e da metodologia proposta por Momigliano e Siniscalco (1982, 1986). A hipótese defendida é que a mudança estrutural se deve ao avanço na participação do subsistema de serviços

(1) Lewis (1954); Kuznets (1955, 1957, 1973); Hirschman (1958); Kaldor (1966).

(2) Franke e Kalmbach (2005); Triplett e Bosworth (2003, 2004); Park e Chan (1989); Markusen (1989).

(3) Este argumento, em favor da redistribuição de atividades antes realizadas pela indústria para atividades de serviços, é defendido principalmente por Chang (2012). 
intermediários no total de horas trabalhadas e não apenas à reclassificação de atividades industriais como atividades de serviços, conforme proposto por Chang (2012).

No decorrer da revisão de literatura foram encontrados apenas cinco estudos que utilizam a metodologia de Momigliano e Siniscalco $(1982,1986)$ para estudar mudança estrutural com ênfase em serviços: Montresor e Marzetti $(2010,2011)$ aplicam essa metodologia para os países da OCDE, com base em um recorte temporal que abrange as décadas de 1980 e 1990; Ciriaci e Palma (2012, 2016) a utilizam para avaliar a ocorrência de mudança estrutural na Alemanha, França, Itália e Reino Unido no período 1995-2005; e, Di Berardino et al. (2018), para estudar as transformações produtivas observadas pela Alemanha, França, Itália, Reino Unido, Espanha e Estados Unidos no período 19952011. As amostras consideradas por esses estudos são compostas por grupos pequenos de países, o que provavelmente se deve ao esforço de tabulação envolvido na aplicação da metodologia. A realização de um estudo mais abrangente, capaz de abarcar todos os países para os quais se encontram dados disponíveis no World Input-Output Database (Feenstra et al., 2015), se justifica, em virtude da relevância na realização de estudos que busquem avançar no debate sobre mudança estrutural.

A amostra utilizada abrange o período 2000-2014, sendo composta por 43 países discriminados em três grupos: Renda baixa, até US\$ 20.000,00 per capita; Renda média, entre US\$ 20.000,00 e US\$ 35.000,00 per capita; e, Renda alta, acima de US\$ 35.000,00 per capita. O elevado tamanho da amostra possibilita a realização de uma análise mais abrangente e que fornece evidências inovadoras sobre o comportamento apresentado pelo subsistema de serviços intermediários e sobre o processo de mudança estrutural.

Os resultados obtidos mostram que mesmo após o controle dos efeitos oriundos da terceirização de atividades industriais para atividades de serviços intermediários, ainda se observa recuo na participação da indústria no total de horas trabalhadas. Essa retração é explicada principalmente pelo aumento na participação do subsistema de serviços intermediários, decorrente do crescente encadeamento vertical desse subsistema. Isto é, pelo avanço na utilização de insumos oriundos de atividades de serviços intermediários no próprio setor de serviços intermediários. Este resultado se mostra bastante esclarecedor sobre os reais contornos assumidos pela desindustrialização e converge com as evidências encontradas pela literatura de inovação: as tecnologias emergentes são cada vez mais intensivas em serviços intermediários, contribuindo para o crescente adensamento e interdependência entre as atividades que compõem este subsistema.

As evidências encontradas também demonstram que a participação da indústria no total de horas trabalhadas no subsistema de serviços intermediários recuou no período analisado. Este resultado se mostra especialmente importante, pois indica que o aumento na utilização de serviços intermediários nas atividades industriais não é acompanhado pela maior utilização de insumos industriais nas atividades de serviços intermediários. Ademais, a Crise do Subprime quebrou a tendência ascendente observada no período 2000-2009, resultando em um cenário de estagnação na participação do subsistema de serviços intermediários no total de horas trabalhadas. Os serviços intermediários dos países com renda média e elevada foram o subsistema mais afetado pela crise, observando-se recuo no seu encadeamento vertical.

Além desta introdução, o artigo possui mais quatro seções. A seção 1 discutirá a importância da indústria e dos serviços intermediários para o desenvolvimento econômico. Na sequência, a seção 
2 formalizará a metodologia utilizada para caracterizar o processo de mudança estrutural exibido pelos países analisados. Em seguida, a seção 3 formalizará os resultados obtidos para os diferentes grupos de países. Concluindo com as considerações finais.

\section{A contribuição da indústria e dos serviços intermediários para o desenvolvimento econômico}

A literatura econômica clássica de mudança estrutural argumenta que o crescimento econômico é explicado pela mudança na composição setorial das economias. O crescimento econômico é percebido como o resultado da migração do setor tradicional (agricultura) para o setor moderno (indústria) ${ }^{4}$. Estes estudos defendem que o estímulo do processo de mudança estrutural em direção a ganhos de participação da indústria na renda nacional é capaz de conduzir as economias para trajetórias de crescimento econômico sustentado. Em especial, Kaldor (1966) defende a capacidade da indústria em promover um processo autodeterminado de crescimento econômico.

Kaldor (1966) argumenta que a indústria é o motor do crescimento econômico. Segundo o autor, os países passam por quatro etapas específicas de industrialização: 1) inicialmente eles produzem bens industriais básicos de consumo; 2) posteriormente passam a exportar estes bens; 3 ) na terceira etapa, eles produzem bens de capital; 4) por fim, eles se tornam exportadores líquidos de bens de capital minimizando inclusive problemas relativos à restrição externa ao crescimento. Conforme os países migram para as fases mais avançadas, a taxa de crescimento econômico se acelera.

Posteriormente, surgiram evidências favoráveis à argumentação de que a participação da indústria no valor adicionado se reduz conforme os países se desenvolvem (Fuchs, 1968). O termo "desindustrialização" foi proposto originalmente por Rowthorn e Ramaswamy (1999), sendo utilizado para mostrar que os países desenvolvidos observam redução na participação dos empregos industriais nos empregos totais. Tregenna (2009) estendeu o conceito de desindustrialização, argumentando que, além da redução dos empregos industriais, estes países também observam a retração na participação do valor adicionado deste setor. Posteriormente, outros autores diagnosticaram a ocorrência de desindustrialização em diferentes países, sendo este fenômeno mensurado através de diferentes indicadores (Squeff, 2012).

Segundo Rowthorn e Ramaswamy (1999), a desindustrialização pode ser provocada por fatores internos aos países ou por fatores externos. Os fatores internos podem ser discriminados em dois, a saber: 1) o crescimento mais rápido da produtividade industrial do que da produtividade registrada pelo setor de serviços; e, 2) a mudança na relação entre a elasticidade-renda da demanda por produtos industriais e serviços. Para Rowthorn e Ramaswamy (1997, p.6), a desindustrialização não deve ser percebida como algo prejudicial, sendo "uma característica inevitável do desenvolvimento econômico". Isto é, a "desindustrialização é simplesmente o resultado natural do processo de desenvolvimento econômico bem-sucedido, e é, em geral, associada com o aumento do padrão de vida." (Rowthorn; Ramaswamy, 1997, p. 14).

Colin Clark (1957), citado por Rowthorn e Ramaswamy (1999), encontra na composição da demanda setorial outra explicação para a redução da participação industrial no emprego. Conforme

(4) Lewis (1954); Kuznets $(1955,1957,1973)$. 
os países se desenvolvem, a parcela da renda gasta em produtos industriais se estabiliza e, posteriormente, recua, o que provoca a elevação na demanda por serviços, estimulando a sua oferta em detrimento dos produtos industriais. Assim, as forças oriundas do lado da demanda resultam em aumento na participação dos serviços no emprego e no valor adicionado. Como consequência, a partir de determinado nível de renda per capita, se observa a redução na participação da indústria no PIB.

Por outro lado, os autores que buscam no lado externo as causas da desindustrialização consideraram que o grau de integração comercial e produtiva dos países também influencia no seu grau de industrialização. Wood (1994) argumenta que as importações de manufaturados dos países em desenvolvimento são altamente intensivas em mão-de-obra. Assim, um aumento equilibrado do comércio norte-sul irá reduzir o emprego industrial no Norte em indústrias menos intensivas em conhecimento e que empregam mais trabalhadores. O número de empregos de baixa qualificação, perdidos com o aumento das importações, ultrapassa em muito os novos postos de trabalho criados nas atividades que contratam mão-de-obra intensiva em conhecimento. Como resultado, a maior integração industrial resulta em diminuição na participação industrial nos empregos.

A especialização em produtos específicos de serviços ou da indústria é outro elemento que pode contribuir para a ocorrência de desindustrialização. A globalização leva alguns países a se especializarem na fabricação de produtos industriais (principalmente China e Alemanha), enquanto outros se especializam em serviços (por exemplo, Estados Unidos e Reino Unido). O resultado é o aumento do emprego industrial no primeiro grupo e a redução do emprego industrial no segundo (Oreiro; Feijó, 2010).

Posteriormente, Palma (2005), com base nas evidências encontradas pela literatura, identifica quatro fontes de desindustrialização: 1. a relação de "U invertido" entre emprego industrial e renda per capita reportada por Rowthorn e Ramaswamy (1999); 2. Presença de relação declinante entre a renda per capita e o emprego industrial ao longo do tempo, devido ao nível decrescente de emprego na indústria associado à renda per capita nos países de alta e média renda (explicado por quatro hipóteses: I. ilusão estatística causada principalmente pela realocação de trabalhadores da manufatura para os serviços; II. redução na elasticidade-renda por manufaturas; III. maior crescimento da produtividade na manufatura e IV. o resultado de uma nova divisão internacional do trabalho); 3. Redução no nível de renda per capita correspondente ao ponto de virada da relação em "U invertido" entre emprego industrial e renda per capita; e, 4. a doença holandesa.

Paralela a essa discussão sobre desindustrialização, surgiram novas evidências na literatura econômica internacional que não reservam somente à indústria a função de motor do desenvolvimento econômico. Essa nova literatura mostra que os serviços intermediários também influenciam nas trajetórias de desenvolvimento. A irrupção de tecnologias disruptivas, relativas ao novo paradigma tecno-econômico (Perez, 2004) que emergiu nas décadas de 1970-80, contribuiu para a ocorrência de diversas modificações na dinâmica econômica, dentre as quais se destacam: aumento no comércio de serviços; crescimento dos serviços de negócios relacionados à gestão das cadeias globais de valor; terceirização e offshore. Todos estes fatores colaboraram para o crescimento dos serviços intermediários; surgimento de novas atividades; incremento do comércio internacional; maior 
especialização e aumento da produtividade. Também, parte substantiva do aumento de produtividade das economias que melhor se inseriram no novo paradigma foi repassada para a indústria ${ }^{5}$.

A terceirização de atividades tecnológicas e produtivas para firmas cada vez mais especializadas em serviços estimulou o crescimento do setor e o seu crescimento viabilizou a maior especialização produtiva, o aumento da produtividade do trabalho e o surgimento de um novo leque de serviços intermediários, resultando na formação de um círculo virtuoso de crescimento, terceirização, especialização e ganho de produtividade ${ }^{6}$. Serviços mais produtivos e de elevada qualidade implicaram em bens industriais mais baratos e de melhor qualidade, resultando em maior competitividade dos países que os produzem ${ }^{7}$.

Deste modo, o desenvolvimento de inovações nos serviços intermediários elevou a produtividade das firmas e isto contribuiu para o surgimento de novas inovações, formando-se um ciclo virtuoso. A força desta relação é crescente, pois quanto maior for o desempenho de uma firma de serviços maior será o seu incentivo a inovar, e quanto mais ela inova mais o seu desempenho se eleva (Cainelli et al., 2006). Ademais, há evidências de que os serviços de negócios estão sujeitos às leis de Kaldor, também sendo capazes de provocar crescimento autossustentado (Giovanini; Arend, 2017; Di Meglio et al., 2015; Dasgupta; Singh, 2007).

Os serviços passaram a ser associados à capacidade de inovação dos países (Miozzo; Soete, 2001). A literatura de serviços intensivos em conhecimento (KIBS) mostra que este setor supre a indústria com o conhecimento necessário à realização de inovações. Estes conhecimentos surgem da interação entre serviços e indústria e não de atividades específicas encontradas isoladamente em apenas um destes setores (Miles et al., 1994, 1995, 2008; Hertog, 2000; Muller, 2001; Czarnitzki et al., 2000).

As evidências encontradas pela literatura de serviços permitem complementar a análise realizada por Kaldor (1966). A migração para atividades industriais mais sofisticadas acelera as taxas de crescimento econômico. Contudo, os serviços intermediários e a indústria são interdependentes, sendo o desenvolvimento conjunto destes setores que resulta em maior crescimento. Ou seja, a indústria demanda o desenvolvimento de soluções específicas oriundas do setor de serviços intermediários. Em caráter complementar, as inovações nestes serviços provocam mudanças na indústria de transformação e demandam o surgimento de novas atividades industriais e de serviços (Gallouj; Weinstein, 1997; Windrum; Tomlinson, 1999; Meliciani et al., 2005).

Nordås (2010) mostra que as indústrias que possuem elevado conteúdo tecnológico são mais intensivas em serviços do que as demais. O aumento na participação do setor de serviços como insumo utilizado pela indústria faz com que este setor se transforme no principal vetor de dinamismo econômico. O seu crescimento determina o crescimento da produtividade industrial e do PIB (Linden et al., 2011; Kendrick, 1985; Nordås; Kin, 2013). Os ganhos de produtividade obtidos pelo setor de serviços também se tornam cada vez mais importantes para garantir a geração de empregos e o

(5) Franke e Kalmbach (2005); Rodrigue (2006); Miozzo e Soete (1999); Francois e Woerz (2008); Berlingieri (2013); Gereffi e Frederick (2010); Cuadrado-Roura e Maroto-Sanchez (2011).

(6) Franke e Kalmbach (2005); Triplett e Bosworth (2003); Triplett e Bosworth (2004); Park e Chan (1989); Markusen (1989).

(7) Berlingieri (2013); Amiti e Wei (2005); Francois e Woerz (2008); Carter (1970) e Barker e Forssell (1992). 
pagamento de salários elevados. Por outro lado, o não desenvolvimento desse setor pode criar entraves que restringem a capacidade de crescimento econômico dos países (Kendrick, 1985).

As evidências apresentadas pela literatura econômica contemporânea mostram que a quantidade de conhecimento produtivo possuída pelos países e as suas capacidades em expandir estes conhecimentos e vinculá-los à indústria determinam as taxas de crescimento econômico observadas. Os serviços intermediários fornecem conhecimentos tecnológicos vitais à indústria, acelerando o crescimento do PIB. O não desenvolvimento destes serviços significa a não "oxigenação" da indústria com conhecimentos tecnológicos necessários. Como resultado, o país não consegue diversificar a sua estrutura produtiva, restringindo seu processo de mudança estrutural e permanecendo defasado tecnologicamente.

Para além, essas evidências permitem o questionamento sobre as reais causas do processo de mudança estrutural e desindustrialização. Será que a retração na participação da indústria é explicada apenas pela redistribuição e surgimento de novas atividades em firmas de serviços intermediários, utilizadas como insumo pela indústria? Ou será que ela se deve à ocorrência de um fenômeno mais amplo, decorrente do aumento na demanda por serviços intermediários provocada pelas novas tecnologias, que resulta em aumento na participação dos serviços intermediários em detrimento dos serviços finais? Este estudo busca respostas para essas perguntas.

\section{Metodologia}

\subsection{A abordagem do subsistema}

O conceito de subsistema foi proposto originalmente por Sraffa (1960, p. 89), sendo as implicações teóricas desse conceito estudadas de forma mais detalhada por Pasinetti (1973). Para esse autor, um subsistema equivale a uma agregação que representa analiticamente todas as atividades (diretas e indiretas) envolvidas na satisfação da demanda final por um bem ou serviço específico, dado o estoque de capital fixo.

Momigliano e Siniscalco $(1982,1986)$ utilizaram o conceito de subsistema para desenvolver uma metodologia que reclassifica qualquer variável de uma base setorial para uma base de subsistema. Essa metodologia é aqui utilizada para identificar a participação dos subsistemas de serviços intermediários e industrial no total de horas trabalhadas. Ela também é utilizada para mensurar a participação dos serviços intermediários na demanda final do subsistema industrial e viceversa, sendo o subsistema industrial discriminado por intensidade tecnológica.

A utilização da abordagem de subsistemas parte do reconhecimento de que a aplicação das categorias de análise "indústria" e "serviços", como empregadas pela literatura clássica dos anos 1940 e 1950, se mostrava adequada ao contexto da época. No entanto, o surgimento das novas tecnologias de comunicação modificou o modo como ocorre a interação indústria-serviços, transformando o processo produtivo e demandando a criação de novas categorias de análise, mais adequadas para a verificação das relações setoriais existentes na atualidade. A abordagem de subsistemas possibilita a criação de categorias de análise mais adequadas ao contexto atual.

A metodologia proposta por Momigliano e Siniscalco $(1982,1986)$ permite a mensuração do montante de emprego em serviços utilizado como demanda intermediária, identificando a destinação 
real dos empregos, o que evita a realização de uma análise do processo de mudança estrutural com base na hipótese de que todos os produtos gerados por determinado setor produtivo possuem como objetivo atender a demanda final do próprio setor. A vantagem apresentada por esta metodologia é que a medida de desindustrialização obtida com a integração vertical das atividades produtivas não é afetada pela terceirização de atividades produtivas e por mudanças na organização interna do sistema econômico.

Essa metodologia transforma a representação das tabelas de insumo-produto, na qual cada setor está vinculado aos demais por relações de compra e venda, em subsistemas verticalmente integrados que utilizam o trabalho como insumo externo para fabricar o produto destinado a satisfazer a demanda final. Esse método pode ser formalizado na seguinte expressão algébrica:

$$
B=(\hat{x})^{-1}(I-A) \hat{f},
$$

em que $(I-A)$ é a matriz de Leontief, cujo elemento $a_{i j}$ mensura o montante de insumos do subsistema $i$ diretamente e indiretamente necessário para se obter uma unidade de produto no ramo $j, x$ é um vetor cujo elemento $x_{i}$ identifica a produção bruta total a preços correntes do ramo $i, f$ é um vetor cujo elemento $f_{i}$ representa o produto total do subsistema $i$ destinado para o consumo final

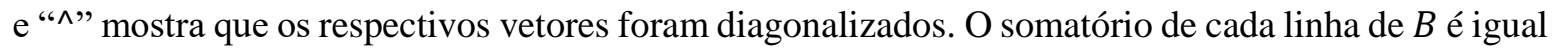
a 1 , de modo que o elemento $b_{i j}$ identifica a proporção da atividade de cada ramo $j$ oriunda de cada subsistema $i$ (Momigliano; Siniscalco, 1982).

Deste modo, B é o operador responsável por realizar a reclassificação de uma variável $h$ de uma base de setor para uma base de subsistema, conforme segue:

$$
\beta=\hat{h} B
$$

em que $\hat{h}$ é a matriz diagonalizada do vetor de horas contratadas. O elemento genérico $h_{i j}$ identifica a quantidade de horas de trabalho que precisam ser utilizadas, direta e indiretamente, pelo setor $i$ para responder à demanda final no subsistema $j$. As matrizes $B$ e $\beta$ não são influenciadas pelos níveis de preços (Rampa, 1982), a comparação do comportamento apresentado por essas matrizes ao longo do tempo identifica as fontes da mudança estrutural em cada subsistema. Como os resultados não são influenciados pela organização interna de cada subsistema, essa representação possibilita comparações entre diferentes sistemas econômicos e a análise da evolução na participação de cada subsistema nos empregos totais da economia.

Assim, a "abordagem do subsistema" possibilita a obtenção de medidas mais adequadas da extensão real do processo de desindustrialização, obtida mediante a divisão do valor resultante da soma das células que compõem cada coluna da Matriz $\beta$ (o total de horas trabalhadas no subsistema) pela soma de todas as células de $\beta$ (o total de horas trabalhadas na economia). Ela também permite a identificação da participação direta e indireta de cada ramo no total de horas trabalhadas em cada subsistema, através da divisão do valor de cada célula de $\beta$ pelo valor da coluna em que a célula se encontra. Este indicador pode ser utilizado para se verificar a ocorrência de modificações na composição interna de cada subsistema. Isto é, se ocorreu uma modificação na utilização direta e indireta nos insumos oriundos de cada ramo. 


\subsection{Amostra utilizada}

Os resultados foram gerados a partir da agregação dos países em três grupos distintos: Renda baixa, até US\$20.000,00 per capita (paridade poder de compra, a preços constantes de 2011); Renda média, entre US\$20.000,00 e US\$ 35.000,00 per capita; e, Renda elevada, acima de US\$ 35.000,00 per capita. Os dados de renda utilizados na classificação foram obtidos para o ano de 2014, sendo extraídos da base de dados do Banco Mundial (2020). O agrupamento dos países de acordo com esses níveis de renda é explicado pelas características apresentadas pela amostra, a qual é composta principalmente por países com nível de renda mais elevado. De modo que a definição dos países e do período de realização da análise é restringida pela disponibilidade dos dados.

Com efeito, apenas sete países apresentaram menos de US\$20.000,00 per capita de renda (Índia, Indonésia, China, Brasil, Bulgária, México e Romênia); 18 países possuem renda entre US\$ 20.000,00 e US\$ 35.000,00 per capita (Hungria, Croácia, Turquia, Grécia, Hungria, Polônia, Rússia, Portugal, Lituânia, Estônia, Eslováquia, Eslovênia, República tcheca, Chipre, Espanha, Malta, Coreia do Sul, Itália) e 18 países, acima de US\$ 35.000,00 (Japão, França, Reino Unido, Finlândia, Bélgica, Canadá, Alemanha, Austrália, Áustria, Suécia, Dinamarca, Países baixos, Irlanda, Estados Unidos, Suíça, Noruega, Luxemburgo e Taiwan).

Os dados utilizados na elaboração dos resultados (Horas trabalhadas e Tabelas de Recursos e Usos) foram extraídos da base de dados do World Input-Output Database (Feenstra et al., 2015). A classificação das atividades industriais por intensidade tecnológica (Baixa, Média-baixa, Média-alta e Alta) foi realizada seguindo as recomendações da OCDE, podendo ser encontrada em Sarra (2019, p. 238). Já a classificação das atividades em serviços finais e intermediários remonta à Francois e Reinert (1996).

\section{Resultados encontrados}

Essa seção se encontra discriminada em duas subseções. A subseção 3.1 compila os resultados encontrados mediante a agregação dos dados disponíveis para os países. Já a subseção 3.2 discrimina os países em grupos distintos, de acordo com o seu nível de renda.

\subsection{Resultados para os países agregados}

A Tabela 1 consolida os dados referentes à taxa de crescimento das horas trabalhadas, discriminadas por grupos de países, para dois níveis distintos de agregação. A primeira parte da Tabela (linhas de 1 a 4) agrega as horas trabalhadas em todos os ramos que compõem cada subsistema, indicando recuo nas horas trabalhadas nos subsistemas de Baixa e de Alta intensidade tecnológica dos países com médio e elevado nível de renda e nos subsistemas de Média-alta intensidade tecnológica dos países com elevado nível de renda, indicando desindustrialização tanto nos países com médio quanto nos com elevado nível de renda.

Já a segunda parte da tabela (linhas de 5 a 8 ) identifica apenas as horas trabalhadas nos ramos industriais, evidenciando retração nas horas trabalhadas na indústria em todos os subsistemas para os países com nível médio e elevado de renda, exceto no subsistema de Média-baixa intensidade tecnológica para os países em nível intermediário de renda. O que provavelmente decorre da terceirização de atividades industriais para países com menor renda. 
Tabela 1

Taxa de crescimento anualizada das horas trabalhadas, discriminadas por grupos de países, período 2000-2014 (\%)

\begin{tabular}{l|ccccccc}
\hline Subsistema & Primário & Baixa & Média-baixa & Média-alta & Alta & Int. & Finais \\
\hline Renda Baixa & $-0,5 \%$ & $2,8 \%$ & $3,4 \%$ & $3,8 \%$ & $0,1 \%$ & $4,0 \%$ & $2,2 \%$ \\
Renda Média & $-2,8 \%$ & $-1,0 \%$ & $1,3 \%$ & $0,5 \%$ & $-0,4 \%$ & $1,4 \%$ & $1,2 \%$ \\
Renda Elevada & $1,0 \%$ & $-1,9 \%$ & $0,6 \%$ & $-0,7 \%$ & $-2,8 \%$ & $0,8 \%$ & $0,4 \%$ \\
\hline Indústria & Primário & Baixa & Média-baixa & Média-alta & Alta & Int. & Finais \\
\hline Renda Baixa & $1,6 \%$ & $3,1 \%$ & $3,2 \%$ & $4,1 \%$ & $1,2 \%$ & $3,7 \%$ & $2,5 \%$ \\
Renda Média & $-4,3 \%$ & $-1,4 \%$ & $0,8 \%$ & $-0,5 \%$ & $-0,9 \%$ & $-0,4 \%$ & $-0,9 \%$ \\
Renda Elevada & $-0,1 \%$ & $-2,3 \%$ & $-0,2 \%$ & $-1,2 \%$ & $-2,2 \%$ & $-2,0 \%$ & $-1,1 \%$ \\
\hline
\end{tabular}

Fonte: Elaboração própria.

Evidencia-se, assim, a robustez e o elevado potencial de contribuição da metodologia utilizada, que demonstra a importância da análise conjunta dos empregos gerados em todos os ramos que compõem cada subsistema, sob o risco de se identificar erroneamente a ocorrência de desindustrialização devido à terceirização de atividades de ramos industriais para ramos de serviços e/ou do aumento no montante de insumos oriundos de atividades de serviços. A Tabela 1 mostra que a desindustrialização atinge subsistemas específicos dos países com renda média e elevada, não se observando um quadro generalizado de desindustrialização, mas apenas um processo de reconfiguração do sistema industrial.

O subsistema Primário é o que apresenta maior integração vertical (Tabela 2), sendo 89\% das horas trabalhadas nesse subsistema oriundas do ramo Primário, seguido pelos subsistemas de Serviços finais e Intermediários, $78 \%$, e $80 \%$, respectivamente. Na indústria, os subsistemas de Baixa e Elevada intensidade tecnológica apresentam maior integração vertical, $49 \%$ e 32\%, respectivamente, sendo os maiores graus de fragmentação produtiva verificados para os subsistemas de Média-baixa e Média-alta intensidade tecnológica, $28 \%$ para ambos. Os subsistemas industriais exibem elevada participação do ramo primário no total de horas trabalhadas, sendo os subsistemas de Média-baixa, 43\%, e Baixa intensidade tecnológica, 28\%, os que possuem maior participação.

Tabela 2

Participação das horas trabalhadas em cada subsistema, dados agregados para todos os países, 2014 (\%)

\begin{tabular}{l|ccccccc}
\hline 2014 & Primário & Baixa & Média-baixa & Média-alta & Alta & Int. & Finais \\
\hline Primário & $89 \%$ & $28 \%$ & $43 \%$ & $22 \%$ & $17 \%$ & $9 \%$ & $4 \%$ \\
Baixa & $2 \%$ & $49 \%$ & $3 \%$ & $4 \%$ & $4 \%$ & $2 \%$ & $2 \%$ \\
Média-baixa & $1 \%$ & $2 \%$ & $28 \%$ & $9 \%$ & $5 \%$ & $3 \%$ & $1 \%$ \\
Média-alta & $1 \%$ & $1 \%$ & $2 \%$ & $28 \%$ & $3 \%$ & $1 \%$ & $0 \%$ \\
Alta & $0 \%$ & $0 \%$ & $0 \%$ & $1 \%$ & $32 \%$ & $0 \%$ & $0 \%$ \\
Int. & $6 \%$ & $14 \%$ & $18 \%$ & $26 \%$ & $28 \%$ & $78 \%$ & $12 \%$ \\
Finais & $2 \%$ & $5 \%$ & $6 \%$ & $10 \%$ & $10 \%$ & $7 \%$ & $80 \%$ \\
\hline
\end{tabular}

Fonte: Elaboração própria. Os resultados compilados nessa tabela foram obtidos mediante a agregação dos dados para todos os países que compõem a amostra, sendo elaborado com o objetivo de se identificar o perfil apresentado conjuntamente por esse grupo de países para o ano de 2014. 
Os resultados compilados na Tabela 2 também mostram que os subsistemas mais sofisticados em termos tecnológicos são os que apresentam maior participação do ramo de serviços intermediários no montante de horas trabalhadas, com destaque para a indústria de Alta intensidade tecnológica, 28\%. Na sequência se encontram os subsistemas de Média-alta, 26\%; Média-baixa, 18\%, e Baixa intensidade, $14 \%$. Serviços finais e o subsistema Primário são os que exibem as menores participações, $12 \%$ e 6\%, respectivamente. Apesar do ramo de Serviços intermediários ser amplamente utilizado como insumo pelos subsistemas industriais o oposto não é válido. Isto é, os ramos industriais apresentam baixa participação direta e indireta no total de horas trabalhadas no subsistema de serviços intermediários, sendo as participações mais elevadas observadas para os ramos menos intensivos, a saber: os ramos industriais de Baixa, 3\%, e Média-baixa, 3\%, intensidade tecnológica.

Já os dados contemplados na Tabela 3 evidenciam a retração na participação dos ramos de Média-baixa e Alta intensidade tecnológica na demanda final de todos os subsistemas, exceto para o Primário. O ramo de Média-alta intensidade tecnológica também registra retração de $-8,4$ pontos percentuais na sua participação nas horas trabalhadas no subsistema de Média-alta e 0,1 pontos percentuais em Serviços intermediários, permanecendo estagnado para os demais subsistemas, exceto pelo avanço em 0,2 e 0,1 pontos percentuais para os subsistemas Primário e de Média-baixa intensidade tecnológica.

Tabela 3

Variação, em pontos percentuais, na participação das horas trabalhadas em cada subsistema entre os anos de 2000 e 2014, dados agregados para todos os países

\begin{tabular}{l|ccccccc}
\hline Variação 2000-2014 & Primário & Baixa & Média-baixa & Média-alta & Alta & Int. & Finais \\
\hline Primário & $-5,1$ & $-5,3$ & 0,7 & 1,6 & 2,6 & $-2,3$ & $-1,2$ \\
Baixa & 0,8 & 1,7 & 0,9 & 0,7 & 0,7 & $-0,5$ & $-0,2$ \\
Média-baixa & 0,4 & $-0,3$ & $-7,1$ & $-0,9$ & $-0,9$ & $-0,4$ & $-0,3$ \\
Média-alta & 0,2 & $-0,0$ & 0,1 & $-8,4$ & 0,0 & $-0,1$ & $-0,1$ \\
Alta & 0,0 & $-0,1$ & $-0,1$ & $-0,1$ & $-6,7$ & $-0,1$ & $-0,0$ \\
Int. & 2,9 & 3,3 & 4,7 & 5,9 & 3,7 & 3,9 & 1,5 \\
Finais & 0,9 & 0,7 & 0,7 & 1,2 & 0,7 & $-0,6$ & 0,4 \\
\hline
\end{tabular}

Fonte: Elaboração própria.

Por outro lado, o ramo de Baixa intensidade tecnológica exibe avanço na sua participação no subsistema Primário, 0,8 pontos percentuais, e nos subsistemas de Baixa, 1,7; Média-baixa, 0,9; Média-alta, 0,7; e Alta intensidade tecnológica, 0,7, apresentando recuo apenas em sua participação nas horas trabalhadas em Serviços intermediários, -0,5, e Finais, -0,2. A participação do ramo de Serviços intermediários também se eleva, em 2,9 pontos percentuais para o subsistema Primário; 3,3, Baixa intensidade tecnológica; 4,7, Média-baixa; 5,9, Média-alta; 3,7, Alta; 3,9, Serviços intermediários e 1,5, Serviços finais, sendo esses dados favoráveis ao argumento de que ocorreu uma redistribuição dos empregos em favor do ramo de Serviços intermediários (Chang, 2012).

Com efeito, os dados referentes à variação na participação de cada ramo nas horas trabalhadas corroboram o argumento de que aumentou a utilização de serviços intermediários nos subsistemas industriais. Esses dados mostram que a indústria, principalmente os subsistemas de Média-alta e Média-baixa intensidade tecnológica, se tornaram mais dependentes dos insumos oriundos do ramo 
de serviços intermediários, provavelmente devido à necessidade de conhecimentos especializados fornecidos por profissionais altamente qualificados presentes nesse ramo.

O aumento na utilização de serviços intermediários não implica em ausência de desindustrialização. A divisão das horas trabalhadas em cada subsistema pelo total de horas trabalhadas evidencia a retração dos subsistemas de Baixa e de Alta intensidade tecnológica, em 1,7 e 0,5 pontos percentuais, respectivamente, de modo que a participação conjunta dos subsistemas industriais no total de horas trabalhadas se reduz de 23,8\%, em 2000, para 21,9\%, em 2014. Por outro lado, a participação do subsistema de Serviços intermediários (Finais) se eleva em 3,2 $(0,9)$ pontos percentuais, de $28,4 \%(39,6 \%)$ para $31,6 \%(41,6 \%)$.

Assim, o avanço dos serviços intermediários não é explicado apenas pela terceirização de atividades industriais. Apesar dos resultados evidenciarem a ocorrência desse fenômeno, eles também demonstram que a retração nas horas trabalhadas na indústria se deve ao aumento nos encadeamentos verticais observados para o subsistema de serviços intermediários. Isto é, o subsistema de serviços intermediário não emerge apenas subordinado à dinâmica industrial, apresentando uma dinâmica própria. Ele tem se elevado em importância, através do avanço no montante de insumos de serviços intermediários que buscam atender a demanda final advinda do próprio subsistema de serviços intermediários.

Este representa um resultado inovador e de suma importância para a compreensão do processo de mudança estrutural observado pelos países. Conforme evidenciado pela literatura especializada em inovação e serviços, a emergência das novas tecnologias de comunicação impulsionou as atividades de serviços, as quais passaram a ser amplamente demandadas (Freeman et al., 2001; Franke; Kalmbach, 2005; Lesher; Nordås, 2006). O que explica o crescente encadeamento vertical desse setor.

Os resultados tabulados na Tabela 3 também mostram que a participação dos demais ramos nas horas trabalhadas no subsistema de Serviços intermediários recua. De modo que esse subsistema registra integração vertical, sendo a variação nas participações de $-2,3$ pontos percentuais para o subsistema Primário; -0,5 para o subsistema de Baixa intensidade tecnológica; -0,4, Média-baixa; 0,1, Média-alta; 3,9, Alta; e -0,1, Serviços intermediários, respectivamente. O recuo na participação dos ramos industriais nas horas trabalhadas no subsistema de serviços intermediários é uma evidência inovadora, convergente com os resultados encontrados por Marzetti e Montresor (2010). Eles mostram que o subsistema de serviços intermediários apresenta uma relação simbiótica com a indústria, mas que a força dessa relação tende a se retrair unilateralmente no longo prazo, por meio da redução na utilização de insumos industriais pelo subsistema de serviços intermediários.

Conforme enfatizado por Marzetti e Montresor (2010), essa linha de argumentação defende que as novas tecnologias de comunicação demandam a utilização de proporções superiores de bens manufaturados (hardware) para o fornecimento de serviços. Esse fenômeno deveria resultar em aumento na participação dos ramos industriais no subsistema de serviços intermediários, implicando no surgimento de crescente simbiose entre indústria e serviços intermediários, argumento não corroborado pelos resultados obtidos.

\subsection{Resultados desagregados para os países}

A Tabela 4 compara as participações nas horas trabalhadas encontradas para os países com renda per capita baixa, menos de US\$ 20.000,00; Média, entre US\$ 20.000,00 e US\$ 35.000,00, e 
Elevada, acima de US\$ 35.000,00. Os países com renda mais elevada apresentam maior participação das horas trabalhadas no ramo de serviços intermediários (Int.) em cada subsistema industrial. Esse ramo responde por $29 \%$ dos empregos gerados no subsistema de Baixa intensidade tecnológica; $31 \%$, no subsistema de média-baixa; $32 \%$, média-alta e $28 \%$, Alta intensidade tecnológica. Os países com renda per capita média, por sua vez, registram participação de $19 \%$ no subsistema de Baixa intensidade tecnológica; 24\%, Média-baixa; 23\%, Média-alta e 24\% Alta. Já os países com renda baixa registram participação de $8 \%$ para o subsistema de Baixa intensidade tecnológica; $2 \%$, Médiabaixa; $4 \%$, Média-alta; e 1\%, Alta.

Tabela 4

Participação das horas trabalhadas em cada subsistema para os países discriminados em grupos de renda, 2014

\begin{tabular}{|c|c|c|c|c|c|c|c|}
\hline Renda elevada & Primário & Baixa & Média-baixa & Média-alta & Alta & Int. & Finais \\
\hline Primário & $51 \%$ & $6 \%$ & $9 \%$ & $2 \%$ & $1 \%$ & $1 \%$ & $1 \%$ \\
\hline Baixa & $3 \%$ & $55 \%$ & $2 \%$ & $2 \%$ & $2 \%$ & $1 \%$ & $1 \%$ \\
\hline Média-baixa & $3 \%$ & $3 \%$ & $48 \%$ & $7 \%$ & $4 \%$ & $2 \%$ & $1 \%$ \\
\hline Média-alta & $2 \%$ & $1 \%$ & $3 \%$ & $48 \%$ & $3 \%$ & $1 \%$ & $1 \%$ \\
\hline Alta & $0 \%$ & $0 \%$ & $1 \%$ & $2 \%$ & $56 \%$ & $0 \%$ & $0 \%$ \\
\hline Int. & $32 \%$ & $29 \%$ & $31 \%$ & $32 \%$ & $28 \%$ & $91 \%$ & $19 \%$ \\
\hline Finais & $9 \%$ & $6 \%$ & $6 \%$ & $7 \%$ & $6 \%$ & $5 \%$ & $76 \%$ \\
\hline Renda média & Primário & Baixa & Média-baixa & Média-alta & Alta & Int. & Finais \\
\hline Primário & $68 \%$ & $7 \%$ & $12 \%$ & $3 \%$ & $1 \%$ & $2 \%$ & $1 \%$ \\
\hline Baixa & $1 \%$ & $53 \%$ & $2 \%$ & $2 \%$ & $3 \%$ & $1 \%$ & $1 \%$ \\
\hline Média-baixa & $2 \%$ & $3 \%$ & $41 \%$ & $7 \%$ & $4 \%$ & $3 \%$ & $1 \%$ \\
\hline Média-alta & $2 \%$ & $2 \%$ & $3 \%$ & $48 \%$ & $5 \%$ & $2 \%$ & $1 \%$ \\
\hline Alta & $0 \%$ & $0 \%$ & $0 \%$ & $1 \%$ & $48 \%$ & $0 \%$ & $0 \%$ \\
\hline Int. & $15 \%$ & $19 \%$ & $24 \%$ & $23 \%$ & $24 \%$ & $78 \%$ & $8 \%$ \\
\hline Finais & $12 \%$ & $16 \%$ & $18 \%$ & $16 \%$ & $15 \%$ & $13 \%$ & $89 \%$ \\
\hline Renda Baixa & Primário & Baixa & Média-baixa & Média-alta & Alta & Int. & Finais \\
\hline Primário & $45 \%$ & $17 \%$ & $12 \%$ & $6 \%$ & $1 \%$ & $14 \%$ & $5 \%$ \\
\hline Baixa & $1 \%$ & $83 \%$ & $1 \%$ & $2 \%$ & $1 \%$ & $6 \%$ & $6 \%$ \\
\hline Média-baixa & $2 \%$ & $7 \%$ & $42 \%$ & $11 \%$ & $1 \%$ & $31 \%$ & $6 \%$ \\
\hline Média-alta & $2 \%$ & $7 \%$ & $4 \%$ & $69 \%$ & $2 \%$ & $10 \%$ & $4 \%$ \\
\hline Alta & $0 \%$ & $4 \%$ & $1 \%$ & $4 \%$ & $80 \%$ & $7 \%$ & $4 \%$ \\
\hline Int. & $2 \%$ & $8 \%$ & $2 \%$ & $4 \%$ & $1 \%$ & $76 \%$ & $7 \%$ \\
\hline Finais & $1 \%$ & $5 \%$ & $2 \%$ & $2 \%$ & $1 \%$ & $10 \%$ & $79 \%$ \\
\hline
\end{tabular}

Fonte: Elaboração própria.

Assim, os dados tabulados corroboram o argumento de que existe uma relação positiva entre o nível de renda e a participação do ramo de serviços intermediários no total de horas trabalhadas em cada subsistema. Esse resultado vai de encontro às evidências observadas pela literatura, a qual mostra que os serviços intermediários se encontram mais presentes nos países com maior renda e nas atividades industriais mais intensivas em termos tecnológicos (Miles, 2008; Muller; Zenker, 2001; Miozzo; Soete, 2001; Lesher; Nordås, 2006; Castellacci, 2008; Nordås, 2008; Savona; Steinmueller, 2013; Arbache, 2015; 2016). Cabe, conquanto, salientar que a maior participação dos serviços 
intermediários na produção dos subsistemas industriais não implica necessariamente em uma relação de causalidade. Isto é, não é possível se inferir, necessariamente, que os países de renda elevada efetuaram o processo de mudança estrutural em decorrência de apresentarem participação maior dos serviços intermediários. A elevação nos serviços pode, inclusive, ser uma consequência e não o elemento responsável pela promoção do processo de mudança estrutural.

Os países com renda per capita elevada também apresentam integração vertical mais elevada para os subsistemas industriais (Baixa, 55\%; Média-baixa, 48\%; Média-alta, 48\%, e Alta, 56\%) e menor participação do ramo primário nas horas trabalhadas nas atividades industriais (Baixa, 6\%; Média-baixa, 9\%; Média-alta, 2\%, e Alta, 1\%). Já os países em patamar intermediário (baixo) de renda exibem participação mais elevada do que os demais para o ramo de Serviços finais (Primário).

Quanto à variação da participação nas horas trabalhadas (Tabela 5), os países com renda elevada registram recuo nos ramos de Baixa e Média-baixa intensidade tecnológica e de Serviços finais para todos os subsistemas.

Tabela 5

Variação na participação das horas trabalhadas em cada subsistema para os países discriminados em grupos de renda, em pontos percentuais, 2000-2014

\begin{tabular}{|c|c|c|c|c|c|c|c|}
\hline Renda elevada & Primário & Baixa & Média-baixa & Média-alta & Alta & Int. & Finais \\
\hline Primário & 0,00 & 0,01 & 0,03 & 0,01 & 0,00 & 0,00 & 0,00 \\
\hline Baixa & $-0,01$ & $-0,03$ & 0,00 & $-0,01$ & $-0,01$ & $-0,01$ & 0,00 \\
\hline Média-baixa & $-0,01$ & $-0,01$ & $-0,06$ & $-0,02$ & $-0,02$ & $-0,01$ & 0,00 \\
\hline Média-alta & 0,00 & 0,00 & 0,00 & $-0,02$ & 0,00 & 0,00 & 0,00 \\
\hline Alta & 0,00 & 0,00 & 0,00 & 0,00 & 0,08 & 0,00 & 0,00 \\
\hline Int. & 0,03 & 0,04 & 0,05 & 0,04 & $-0,03$ & 0,03 & 0,03 \\
\hline Finais & $-0,01$ & $-0,01$ & $-0,01$ & 0,00 & $-0,02$ & $-0,01$ & $-0,02$ \\
\hline Renda média & Primário & Baixa & Média-baixa & Média-alta & Alta & Int. & Finais \\
\hline Primário & $-0,02$ & $-0,02$ & 0,02 & 0,00 & 0,00 & 0,00 & 0,00 \\
\hline Baixa & 0,00 & 0,00 & 0,00 & 0,00 & 0,01 & $-0,01$ & 0,00 \\
\hline Média-baixa & 0,00 & 0,00 & $-0,03$ & 0,00 & 0,00 & $-0,01$ & 0,00 \\
\hline Média-alta & $-0,01$ & 0,00 & $-0,01$ & $-0,08$ & $-0,01$ & $-0,01$ & 0,00 \\
\hline Alta & 0,00 & 0,00 & 0,00 & 0,00 & $-0,05$ & 0,00 & 0,00 \\
\hline Int. & 0,00 & 0,03 & 0,03 & 0,06 & 0,06 & 0,01 & 0,01 \\
\hline Finais & 0,03 & 0,00 & $-0,01$ & 0,02 & $-0,01$ & 0,00 & 0,00 \\
\hline Renda baixa & Primário & Baixa & Média-baixa & Média-alta & Alta & Int. & Finais \\
\hline Primário & $-0,10$ & $-0,01$ & 0,05 & 0,02 & 0,00 & 0,04 & 0,00 \\
\hline Baixa & 0,00 & $-0,01$ & 0,00 & 0,00 & 0,00 & 0,01 & 0,00 \\
\hline Média-baixa & 0,00 & $-0,01$ & 0,00 & 0,00 & $-0,01$ & 0,02 & $-0,01$ \\
\hline Média-alta & $-0,01$ & $-0,01$ & 0,00 & 0,05 & $-0,01$ & $-0,01$ & $-0,02$ \\
\hline Alta & 0,00 & 0,00 & 0,00 & 0,00 & $-0,01$ & 0,01 & $-0,01$ \\
\hline Int. & 0,00 & $-0,01$ & 0,00 & 0,00 & $-0,01$ & 0,03 & $-0,01$ \\
\hline Finais & 0,00 & 0,00 & 0,00 & 0,00 & $-0,01$ & 0,02 & $-0,01$ \\
\hline
\end{tabular}

Fonte: Elaboração própria. 
O ramo de Serviços intermediários é o único que exibe avanço consistente em sua participação, sendo que a participação do ramo Primário nos subsistemas de Baixa, Média-baixa e Média-alta intensidade tecnológica também se eleva. A participação do ramo de serviços intermediários avança em todos os subsistemas para os países em patamar intermediário de renda, sendo acompanhado pela elevação em subsistemas específicos dos ramos Primário (Média-baixa, 0,02 pontos percentuais) e de Serviços finais (Primário, 0,03 e Média-alta, 0,02). O ramo de Média-alta intensidade tecnológica é o que registra maior retração em sua participação nos distintos subsistemas.

Em relação aos países com baixo nível de renda, o ramo de Serviços intermediários permanece estagnado, observando-se uma dinâmica de mudança estrutural mais específica a cada subsistema, com destaque para o avanço no subsistema de serviços intermediários. Assim, enquanto os países em patamar intermediário e elevado de renda observam avanço na participação do subsistema de serviços intermediários no montante de horas trabalhadas, os países com menor nível de renda registram avanço na participação dos insumos industriais no subsistema de serviços intermediários, de modo que o padrão de mudança estrutural registrado pelos países com baixo nível de renda é distinto do observado pelos países com renda acima de US\$20.000,00 per capita, sendo as maiores modificações na estrutura produtiva explicadas pelo comportamento dos serviços intermediários ${ }^{8}$.

Os dados compilados na Tabela 6 mostram que a participação dos subsistemas industriais no total de horas trabalhadas nos países com renda elevada (linha 2) recua paulatinamente, de $19 \%$ em 2000 para $17 \%$ em 2008, registrando um rápido recuo para $15 \%$ em 2009, ano a partir do qual a tendência de recuo nesse indicador é suavizada. Por outro lado, a participação das horas trabalhadas no subsistema de Serviços intermediários, em relação ao total de horas trabalhadas (linha 3), apresenta tendência crescente, ocorrendo uma quebra na tendência, em 2009, para taxas mais suaves de crescimento. Este comportamento é acompanhado pela utilização de insumos do ramo de serviços intermediários no próprio subsistema de serviços intermediários (linha 8), a qual se eleva de $87 \%$ em 2000 para $91 \%$ em 2010, mas registra leve recuo no período posterior, para $90 \%$ em 2014 . A participação do ramo de serviços intermediários nos subsistemas industriais (linhas de 4 a 7) se eleva de forma consistente ao longo de todo o período para os subsistemas de Média-baixa e Média-alta intensidade tecnológica, enquanto a participação no subsistema de Baixa intensidade tecnológica estagna a partir de 2011 e no subsistema de Alta intensidade recua, de 30\% em 2001 para 24\% em 2014. Já a participação dos ramos industriais no subsistema de serviços intermediários (linhas de 9 a 12) retrocede ao longo de todo o período, com destaque para a retração na participação dos subsistemas de Média-baixa intensidade, de 2,6\% em 2000 para 1,7\% em 2014, e de Baixa intensidade, de 1,7\% em 2000 para $1 \%$ em 2014.

(8) Este resultado é decorrente da presença da Indonésia entre esses países desse grupo. 
Adilson Giovanini

Tabela 6

Evolução dos indicadores construídos ao longo do período 2000-2014 (\%)

\begin{tabular}{|c|c|c|c|c|c|c|c|c|c|c|c|c|c|c|c|c|}
\hline & Indicador & 2000 & 2001 & 2002 & 2003 & 2004 & 2005 & 2006 & 2007 & 2008 & 2009 & 2010 & 2011 & 2012 & 2013 & 2014 \\
\hline \multirow{11}{*}{$\begin{array}{l}\text { Renda } \\
\text { alta }\end{array}$} & $\begin{array}{l}\text { Ind. (\% } \\
\text { total) }\end{array}$ & $19 \%$ & $18 \%$ & $18 \%$ & $17 \%$ & $17 \%$ & $17 \%$ & $17 \%$ & $17 \%$ & $17 \%$ & $15 \%$ & $15 \%$ & $15 \%$ & $15 \%$ & $15 \%$ & $15 \%$ \\
\hline & Int. ( $\%$ total $)$ & $36 \%$ & $37 \%$ & $37 \%$ & $37 \%$ & $37 \%$ & $38 \%$ & $38 \%$ & $38 \%$ & $38 \%$ & $39 \%$ & $39 \%$ & $39 \%$ & $39 \%$ & $39 \%$ & $39 \%$ \\
\hline & Ind. (Baixa) & $24 \%$ & $25 \%$ & $26 \%$ & $26 \%$ & $26 \%$ & $27 \%$ & $27 \%$ & $27 \%$ & $28 \%$ & $28 \%$ & $28 \%$ & $29 \%$ & $29 \%$ & $29 \%$ & $29 \%$ \\
\hline & $\begin{array}{l}\text { Ind. (Média- } \\
\text { baixa) }\end{array}$ & $25 \%$ & $26 \%$ & $26 \%$ & $26 \%$ & $27 \%$ & $27 \%$ & $28 \%$ & $28 \%$ & $29 \%$ & $28 \%$ & $29 \%$ & $29 \%$ & $29 \%$ & $30 \%$ & $30 \%$ \\
\hline & $\begin{array}{l}\text { Ind. (Média- } \\
\text { alta) }\end{array}$ & $27 \%$ & $28 \%$ & $28 \%$ & $28 \%$ & $28 \%$ & $29 \%$ & $29 \%$ & $30 \%$ & $30 \%$ & $29 \%$ & $29 \%$ & $30 \%$ & $30 \%$ & $30 \%$ & $31 \%$ \\
\hline & Ind. (Alta) & $29 \%$ & $30 \%$ & $29 \%$ & $28 \%$ & $28 \%$ & $28 \%$ & $28 \%$ & $28 \%$ & $27 \%$ & $27 \%$ & $26 \%$ & $26 \%$ & $25 \%$ & $24 \%$ & $24 \%$ \\
\hline & $\begin{array}{l}\text { Integração } \\
\text { vertical }\end{array}$ & $87 \%$ & $88 \%$ & $89 \%$ & $89 \%$ & $89 \%$ & $89 \%$ & $89 \%$ & $89 \%$ & $89 \%$ & $90 \%$ & $91 \%$ & $91 \%$ & $91 \%$ & $90 \%$ & $90 \%$ \\
\hline & Int. (Baixa) & $2 \%$ & $2 \%$ & $1 \%$ & $1 \%$ & $1 \%$ & $1 \%$ & $1 \%$ & $1 \%$ & $1 \%$ & $1 \%$ & $1 \%$ & $1 \%$ & $1 \%$ & $1 \%$ & $1 \%$ \\
\hline & $\begin{array}{l}\text { Int. (Média- } \\
\text { baixa) }\end{array}$ & $3 \%$ & $2 \%$ & $2 \%$ & $2 \%$ & $2 \%$ & $2 \%$ & $2 \%$ & $2 \%$ & $2 \%$ & $2 \%$ & $2 \%$ & $2 \%$ & $2 \%$ & $2 \%$ & $2 \%$ \\
\hline & $\begin{array}{l}\text { Int. (Média- } \\
\text { alta) }\end{array}$ & $1 \%$ & $1 \%$ & $1 \%$ & $1 \%$ & $1 \%$ & $1 \%$ & $1 \%$ & $1 \%$ & $1 \%$ & $1 \%$ & $1 \%$ & $1 \%$ & $1 \%$ & $1 \%$ & $1 \%$ \\
\hline & Int. (Alta) & $0 \%$ & $0 \%$ & $0 \%$ & $0 \%$ & $0 \%$ & $0 \%$ & $0 \%$ & $0 \%$ & $0 \%$ & $0 \%$ & $0 \%$ & $0 \%$ & $0 \%$ & $0 \%$ & $0 \%$ \\
\hline \multirow{11}{*}{$\begin{array}{l}\text { Renda } \\
\text { média }\end{array}$} & $\begin{array}{l}\text { Ind. (\% } \\
\text { total) }\end{array}$ & $22 \%$ & $21 \%$ & $21 \%$ & $20 \%$ & $21 \%$ & $20 \%$ & $20 \%$ & $20 \%$ & $19 \%$ & $18 \%$ & $19 \%$ & $19 \%$ & $19 \%$ & $19 \%$ & $19 \%$ \\
\hline & Int. ( $\%$ total $)$ & $23 \%$ & $24 \%$ & $24 \%$ & $24 \%$ & $25 \%$ & $25 \%$ & $26 \%$ & $26 \%$ & $26 \%$ & $27 \%$ & $26 \%$ & $27 \%$ & $27 \%$ & $27 \%$ & $27 \%$ \\
\hline & Ind. (Baixa) & $15 \%$ & $15 \%$ & $15 \%$ & $15 \%$ & $15 \%$ & $15 \%$ & $15 \%$ & $16 \%$ & $15 \%$ & $16 \%$ & $16 \%$ & $17 \%$ & $17 \%$ & $18 \%$ & $18 \%$ \\
\hline & $\begin{array}{l}\text { Ind. (Média- } \\
\text { baixa) }\end{array}$ & $20 \%$ & $19 \%$ & $19 \%$ & $21 \%$ & $20 \%$ & $20 \%$ & $20 \%$ & $20 \%$ & $20 \%$ & $20 \%$ & $21 \%$ & $22 \%$ & $23 \%$ & $23 \%$ & $23 \%$ \\
\hline & $\begin{array}{l}\text { Ind. (Média- } \\
\text { alta) }\end{array}$ & $16 \%$ & $17 \%$ & $17 \%$ & $17 \%$ & $17 \%$ & $17 \%$ & $18 \%$ & $18 \%$ & $19 \%$ & $20 \%$ & $20 \%$ & $21 \%$ & $21 \%$ & $22 \%$ & $22 \%$ \\
\hline & Ind. (Alta) & $17 \%$ & $17 \%$ & $18 \%$ & $19 \%$ & $20 \%$ & $20 \%$ & $20 \%$ & $19 \%$ & $20 \%$ & $22 \%$ & $22 \%$ & $23 \%$ & $23 \%$ & $23 \%$ & $23 \%$ \\
\hline & $\begin{array}{l}\text { Integração } \\
\text { vertical }\end{array}$ & $74 \%$ & $73 \%$ & $74 \%$ & $74 \%$ & $74 \%$ & $74 \%$ & $73 \%$ & $73 \%$ & $73 \%$ & $73 \%$ & $73 \%$ & $74 \%$ & $75 \%$ & $75 \%$ & $75 \%$ \\
\hline & Int. (Baixa) & $2 \%$ & $2 \%$ & $2 \%$ & $2 \%$ & $2 \%$ & $2 \%$ & $2 \%$ & $2 \%$ & $2 \%$ & $2 \%$ & $2 \%$ & $2 \%$ & $1 \%$ & $1 \%$ & $1 \%$ \\
\hline & $\begin{array}{l}\text { Int. (Média- } \\
\text { baixa) }\end{array}$ & $3 \%$ & $3 \%$ & $3 \%$ & $3 \%$ & $3 \%$ & $3 \%$ & $3 \%$ & $3 \%$ & $3 \%$ & $3 \%$ & $3 \%$ & $3 \%$ & $3 \%$ & $3 \%$ & $3 \%$ \\
\hline & $\begin{array}{l}\text { Int. (Média- } \\
\text { alta) }\end{array}$ & $2 \%$ & $2 \%$ & $2 \%$ & $2 \%$ & $2 \%$ & $2 \%$ & $2 \%$ & $2 \%$ & $2 \%$ & $2 \%$ & $2 \%$ & $1 \%$ & $1 \%$ & $1 \%$ & $1 \%$ \\
\hline & Int. (Alta) & $0 \%$ & $0 \%$ & $0 \%$ & $0 \%$ & $0 \%$ & $0 \%$ & $0 \%$ & $0 \%$ & $0 \%$ & $0 \%$ & $0 \%$ & $0 \%$ & $0 \%$ & $0 \%$ & $0 \%$ \\
\hline \multirow{11}{*}{$\begin{array}{l}\text { Renda } \\
\text { baixa }\end{array}$} & $\begin{array}{l}\text { Ind. }(\% \\
\text { total) }\end{array}$ & $23 \%$ & $22 \%$ & $23 \%$ & $24 \%$ & $24 \%$ & $23 \%$ & $24 \%$ & $24 \%$ & $23 \%$ & $23 \%$ & $23 \%$ & $23 \%$ & $24 \%$ & $24 \%$ & $24 \%$ \\
\hline & Int. ( $\%$ total $)$ & $20 \%$ & $20 \%$ & $20 \%$ & $20 \%$ & $21 \%$ & $21 \%$ & $22 \%$ & $22 \%$ & $23 \%$ & $23 \%$ & $24 \%$ & $24 \%$ & $24 \%$ & $24 \%$ & $25 \%$ \\
\hline & Ind. (Baixa) & $10 \%$ & $10 \%$ & $10 \%$ & $11 \%$ & $11 \%$ & $10 \%$ & $11 \%$ & $10 \%$ & $10 \%$ & $11 \%$ & $11 \%$ & $11 \%$ & $11 \%$ & $12 \%$ & $12 \%$ \\
\hline & $\begin{array}{l}\text { Ind. (Média- } \\
\text { baixa) }\end{array}$ & $10 \%$ & $12 \%$ & $12 \%$ & $13 \%$ & $13 \%$ & $13 \%$ & $11 \%$ & $10 \%$ & $10 \%$ & $10 \%$ & $10 \%$ & $10 \%$ & $10 \%$ & $10 \%$ & $11 \%$ \\
\hline & $\begin{array}{l}\text { Ind. (Média- } \\
\text { alta) }\end{array}$ & $17 \%$ & $19 \%$ & $18 \%$ & $19 \%$ & $19 \%$ & $19 \%$ & $19 \%$ & $18 \%$ & $18 \%$ & $17 \%$ & $17 \%$ & $17 \%$ & $17 \%$ & $18 \%$ & $19 \%$ \\
\hline & Ind. (Alta) & $18 \%$ & $19 \%$ & $20 \%$ & $21 \%$ & $21 \%$ & $20 \%$ & $20 \%$ & $20 \%$ & $19 \%$ & $19 \%$ & $19 \%$ & $19 \%$ & $19 \%$ & $20 \%$ & $20 \%$ \\
\hline & $\begin{array}{l}\text { Integração } \\
\text { vertical }\end{array}$ & $61 \%$ & $63 \%$ & $63 \%$ & $63 \%$ & $63 \%$ & $63 \%$ & $62 \%$ & $62 \%$ & $62 \%$ & $61 \%$ & $62 \%$ & $63 \%$ & $64 \%$ & $65 \%$ & $65 \%$ \\
\hline & Int. (Baixa) & $1 \%$ & $1 \%$ & $1 \%$ & $2 \%$ & $2 \%$ & $2 \%$ & $1 \%$ & $1 \%$ & $1 \%$ & $1 \%$ & $1 \%$ & $1 \%$ & $2 \%$ & $2 \%$ & $2 \%$ \\
\hline & $\begin{array}{l}\text { Int. (Média- } \\
\text { baixa) }\end{array}$ & $3 \%$ & $3 \%$ & $3 \%$ & $3 \%$ & $3 \%$ & $3 \%$ & $3 \%$ & $3 \%$ & $3 \%$ & $3 \%$ & $3 \%$ & $3 \%$ & $3 \%$ & $3 \%$ & $3 \%$ \\
\hline & $\begin{array}{l}\text { Int. (Média- } \\
\text { alta) }\end{array}$ & $1 \%$ & $1 \%$ & $1 \%$ & $1 \%$ & $1 \%$ & $1 \%$ & $1 \%$ & $1 \%$ & $1 \%$ & $1 \%$ & $1 \%$ & $1 \%$ & $1 \%$ & $1 \%$ & $1 \%$ \\
\hline & Int. (Alta) & $0 \%$ & $0 \%$ & $0 \%$ & $0 \%$ & $0 \%$ & $0 \%$ & $0 \%$ & $0 \%$ & $0 \%$ & $0 \%$ & $0 \%$ & $0 \%$ & $0 \%$ & $0 \%$ & $0 \%$ \\
\hline
\end{tabular}

Fonte: Elaboração própria, *O parêntese identifica a atividade utilizada como insumo. 
Os países em patamar intermediário de renda também enfrentam retração na participação conjunta dos subsistemas industriais para o total de horas trabalhadas no período $2000-2009$, de $22 \%$ para 18\%, com elevação no período 2010-2011, para 19\%, patamar em torno do qual permanece até 2014. Por outro lado, a participação do subsistema de serviços intermediários avança de forma consistente ao longo de todo o período, não sendo acompanhada pela participação do ramo de serviços intermediários em relação ao total de horas trabalhadas nesse subsistema, a qual se reduz de $74 \%$ em 2003 para $73 \%$ em 2008, avançando para $75 \%$ em 2014. A participação das horas trabalhadas no ramo de serviços intermediários apresenta tendência de alta para todos os subsistemas industriais discriminados por intensidade tecnológica, enquanto a participação dos ramos industriais no total de horas trabalhadas nos subsistemas de serviços intermediários retrocede para todos os ramos.

Os países com baixo nível de renda registram oscilação na participação do subsistema industrial no total de empregos, a qual se eleva de $23 \%$ em 2000 para 24\% em 2014. Em contrapartida, o subsistema de serviços intermediários registra avanço consistente na sua participação no total de horas trabalhadas, de $20 \%$ em 2000 para 25\% em 2014, com a participação dos insumos do próprio ramo de serviços intermediários avançando de $61 \%$ em 2000 para 63\% em 2005, retrocedendo para $61 \%$ em 2009, tendência que é quebrada mediante o avanço para $65 \%$ em 2014 . Já a participação do ramo de serviços intermediários nas horas trabalhadas na indústria retrocede entre 2003 e 2009, avançando timidamente a partir de 2009, enquanto a participação dos ramos industriais no total de horas trabalhadas no subsistema de serviços intermediários exibe leve tendência de crescimento ao longo do período como um todo.

O Apêndice A.1 realiza uma análise da participação do ramo de serviços intermediários no total de horas trabalhadas para cada subsistema industrial, sendo os dados desagregados por país. Os resultados encontrados apresentam importantes indícios de que os países com maior queda nas participações do ramo de serviços intermediários são os que possuem maior renda per capita, sendo os subsistemas industriais mais sofisticados os mais impactados.

Já o Apêndice A.2 compila a taxa de crescimento da participação no total de horas trabalhadas para cada subsistema discriminado por intensidade tecnológica. Esse indicador evidencia a ocorrência de amplo processo de desindustrialização, que atinge a totalidade dos países, 42, para o subsistema de Baixa intensidade tecnológica; 21 países, Média-baixa intensidade tecnológica; 24, Média-alta e 30, Alta. Ademais, se observa um viés em direção aos países com maior nível de renda, principalmente no tocante ao recuo na participação dos empregos nos subsistemas de serviços intermediários e nas indústrias com maior intensidade tecnológica. Essa é uma evidência adicional de que o aumento na participação dos serviços intermediários nos subsistemas industriais ocorre concomitante à retração na participação desses subsistemas nos empregos totais.

No entanto, as evidências que encontramos sugerem um processo de mudança estrutural mais amplo, uma vez que a retração na participação dos ramos industriais nas horas trabalhadas não é explicada somente pelo avanço na participação do ramo de serviços intermediários nos subsistemas industriais, mas principalmente pela retração na participação dos subsistemas industriais combinado com o avanço na participação do subsistema de serviços intermediários. Esse resultado não reduz a importância da indústria, dado que a mudança estrutural ocorre de forma lenta e paulatina, sendo observável apenas no longo prazo. 
Essa tendência se mostra estável ao longo de todo o período em análise. Nesse sentido, os resultados mostram que a desindustrialização não decorre da mera reclassificação de atividades industriais, conforme defendido por Chang (2012). O processo de mudança estrutural é mais abrangente, sendo explicado pela mudança na dinâmica setorial decorrente das novas tecnologias em emergência. Conforme enfatizado por Hidalgo (2011) e Arthur (2013), o surgimento de tecnologias promove a regeneração dos setores preexistentes, gerando uma nova dinâmica de mudança estrutural, a qual, apesar de lenta, se mostra mais favorável a determinadas atividades e setores produtivos.

\section{Considerações finais}

A literatura de mudança estrutural defende que maiores estímulos à indústria conseguem acelerar as taxas de crescimento econômico. No entanto, com a emergência das novas tecnologias de comunicação, surgiram evidências de que os serviços intermediários são utilizados de forma crescente como insumo industrial, observando-se um processo de terceirização de atividades industriais para firmas especializadas em serviços. Dadas essas evidências, esse estudo possui como objetivo analisar as características assumidas pelo processo de mudança estrutural ocorrido no limiar do século XXI, verificando se a tendência de avanço na participação dos serviços intermediários ainda se confirma após o controle do efeito decorrente da terceirização de atividades industriais.

A metodologia proposta por Momigliano e Siniscalco $(1982,1986)$ é utilizada para caracterizar o processo de mudança estrutural apresentado pelas 43 maiores economias mundiais no período 2000-2014. Essa metodologia possibilita verificar se a redução na participação da indústria e a tendência de elevação na participação dos serviços intermediários é robusta, ou se esse fenômeno é decorrente apenas da terceirização de atividades industriais para firmas de serviços intermediários.

Esse estudo apresenta um conjunto inovador de resultados, que fornecem evidências esclarecedoras sobre as características assumidas pelo processo de mudança estrutural. A análise da taxa de crescimento no total de horas trabalhadas para o período 2000-2014, com base na agregação dos dados de todos os países, demonstra que a retração na participação dos ramos industriais não implica, necessariamente, em redução na importância da indústria, uma vez que o número de horas trabalhadas no subsistema como um todo se eleva. A redução das horas trabalhadas nos ramos industriais ocorre concomitante ao aumento nas horas trabalhadas nos demais ramos. Apenas os subsistemas industriais de Alta e Média-alta intensidade tecnológica dos países com renda elevada e o subsistema industrial de Alta intensidade tecnológica dos países em patamar intermediário de renda registram recuo nas horas trabalhadas. Assim, a retração nas horas trabalhadas é observada apenas para os países com maior nível de renda e nos subsistemas industriais mais avançados.

No entanto, os subsistemas de Baixa e de Alta intensidade tecnológica registram retração em suas participações no total de horas trabalhadas. A apreciação conjunta dos subsistemas industriais também revela redução da participação desses subsistemas no total de horas trabalhadas entre os anos de 2000 e 2014. Assim, os resultados agregados evidenciam a importância assumida pelos serviços intermediários, demonstrando que o grau de integração vertical e a participação desse subsistema no total de horas trabalhadas se elevam no período analisado. O montante de Serviços intermediários utilizados pelos subsistemas industriais também se eleva, evidenciando a contribuição crescente dessas atividades para a produção industrial. 
Cabe salientar que o avanço do subsistema de serviços, em termos de formação de um corpo cada vez mais robusto de atividades interconectadas, pode se elevar ainda mais nas próximas décadas com a disseminação de tecnologias mais intensivas em serviços. Entre essas tecnologias cabe citar: as redes sociais; Big data; inteligência artificial; aprendizado de máquina e Blockchain. $\mathrm{O}$ avanço destas tecnologias e das tecnologias correlacionadas a elas possivelmente irá demandar o surgimento de diferentes serviços especializados, contribuindo para que o grau de encadeamento vertical do subsistema de serviços se eleve ainda mais. O resultado é a ocorrência de um possível processo de mudança setorial caracterizado pelo lento aumento na participação do subsistema de serviços intermediários nas horas trabalhadas. As novas tendências tecnológicas também contribuem para o avanço na participação dos serviços intermediários como insumo industrial, principalmente com a elevação na utilização de tecnologias intensivas em serviços, como a Internet das coisas, Big Data, inteligência artificial, aprendizagem de máquina, impressão 3D e armazenagem em nuvem.

A divisão dos países em três grupos distintos, de acordo com a renda, revela que todos os grupos exibem tendência de elevação na participação do ramo de serviços intermediários no total de horas trabalhadas nos subsistemas industriais discriminados por intensidade tecnológica, sendo a participação dos serviços intermediários no subsistema de elevada intensidade tecnológica o único indicador que registra recuo para os países com renda Alta e Baixa. Também se observa tendência de elevação na participação do subsistema de serviços intermediários no total de horas trabalhadas. As evidências coletadas apontam para uma tendência de elevação na participação dos serviços intermediários nos subsistemas industriais. O subsistema de serviços finais também registra avanço na sua participação, apesar dessa tendência ser mais tímida do que a observada para o subsistema de serviços intermediários. Assim, a principal força responsável por promover a mudança estrutural parece ser o efeito oriundo da demanda crescente das novas tecnologias por conhecimentos fornecidos por atividades de serviços intermediários e não o aumento na demanda por serviços finais decorrente do aumento na renda per capita, de modo que os resultados caminham no sentido de indicar que a desindustrialização decorre dessa maior demanda por conhecimentos, que promove o aumento na participação dos serviços intermediários.

Os resultados levantados ao longo deste estudo apresentam algumas evidências inovadoras sobre as características assumidas pelo processo de mudança estrutural no século XXI, não possuindo caráter conclusivo. Eles demonstram a necessidade de estudos futuros que, através da adoção de outras metodologias, corroborem o argumento de que a mudança estrutural é explicada pelo aumento na participação dos serviços intermediários. Fica como sugestão para trabalhos futuros a realização de uma reflexão mais aprofundada acerca das implicações teóricas dos resultados encontrados. O impacto da Crise do Subprime sobre a trajetória de mudança estrutural também representa importante tema que demanda estudos adicionais.

\section{Referências bibliográficas}

AMITI, M.; WEI, S. Fear of service outsourcing: is it justified? Economic Policy, v. 20, n. 42, p. 308$347,2005$. 
ARBACHE, J. Produtividade no setor de serviços. In: De NEGRI, F.; CAVALCANTE, L. R. (Ed.). Produtividade no Brasil: desempenho e determinantes. Brasília: Instituto de Pesquisa Econômica Aplicada, 2015. v. 2, p. 277-300.

ARBACHE, J. The contribution of services to manufacturing competitiveness in Brasil. In: HUALDE, A.; HERNEEZ, R.; MULDER, N.; SAUVÉ, P. (Ed.). Innovation and internationalization in Latin America Services. Santiago de Chile: Cepal, 2016.

ARTHUR, W. Brian. Complexity economics. Complexity and the economy, 2013.

BANCO MUNDIAL. GDP per capita, PPP (constant 2011 international \$). World Development Indicators. 2020. Disponível em: https://data.worldbank.org/indicator/NY.GDP.PCAP.PP.KD?locations=IN. Acesso em: 17 abr. 2020.

BARKER, T.; FORSSELL, O. Manufacturing, services and structural change, 1979-1984. In: STRUCTURAL change in the UK economy. Cambridge University Press, 1992.

BERLINGIERI, G. Essays on international trade and firm organization. 2013. Tese (PhD)Department of Economics of the London School of Economics. London, Dic. 2013.

CAINELLI, G.; EVANGELISTA, R.; SAVONA, Maria. Innovation and economic performance in services: a firm-level analysis. Cambridge Journal of Economics, v. 30, n. 3, p. 435-458, 2006.

CARTER, A. P. Structural change in the American economy. Harvard University Press, 1970.

CASTELLACCI, F. Technological paradigms, regimes and trajectories: Manufacturing and service industries in a new taxonomy of sectoral patterns of innovation. Research Policy, v. 37, n. 6, p. 978994, 2008.

CHANG, H. J. The manufacturing sector and the future of Malaysia's economic development. Journal Pengurusan, v. 35, 2012.

CIRIACI, Daria; PALMA, Daniela. To what extent are knowledge-intensive business services contributing to manufacturing? A subsystem analysis. IPTS working papers on Corporate R\&D and Innovation, 2012.

CIRIACI, Daria; PALMA, Daniela. Structural change and blurred sectoral boundaries: assessing the extent to which knowledge-intensive business services satisfy manufacturing final demand in Western countries. Economic Systems Research, v. 28, n. 1, p. 55-77, 2016.

CUADRADO-ROURA, J. R.; MAROTO-SANCHEZ, A. Regional productivity growth in European countries. The role of services. In: ERSA conference papers. European Regional Science Association, 2011.

CZARNITZKI, D.; RAMMER, C.; SPIELKAMP, A. Intera ktionzwischen Wissenschaft und Wirtschaft in Deutschland: ErgebnisseeinerUmfragebeiHochschulenundöffentlichenForschungseinrichtungen. ZEW-Dokumentation, 2000.

DASGUPTA, S.; SINGH, A. Manufacturing, services and premature deindustrialization in developing countries: A Kaldorian analysis. In: ADVANCING Development. Palgrave Macmillan UK, 2007. p. 435-454. 
DI BERARDINO, Claudio et al. Analyzing the production structure by the subsystem approach to the input-output model: a cross-country perspective. Economics Bulletin, v. 38, n. 1, p. 297-308, 2018.

DI CAGNO, D.; MELICIANI, V. Do inter-sectoral flows of services matter for productivity growth? An input/output analysis of OCDE countries. Economics of Innovation and New Technology, v. 14, n. 3, p. 149-171, 2005.

DI MEGLIO, G. et al. Services in developing economies: a new chance for catching-up? 2015. SWPS 2015-32. Available at: $\underline{\text { https://ssrn.com/abstract }=2744647}$ or http://dx.doi.org/10.2139/ssrn.2744647.

FEENSTRA, Robert C.; INKLAAR, Robert; TIMMER , Marcel P. The next generation of the Penn World Table. American Economic Review, v. 105, n. 10, p. 3150-3182, 2015.

FRANCOIS, J.; WOERZ, J. Producer services, manufacturing linkages, and trade. Journal of Industry, Competition and Trade, v. 8, n. 3-4, p. 199-229, Out. 2008.

FRANCOIS, Joseph; REINERT, Kenneth. The role of services in the structure of production and trade: stylized facts from a cross-country analysis. Asia-Pacific Economic Review, v. 2, n. 1, p. 3543, 1996.

FRANKE, R.; KALMBACH, P. Structural change in the manufacturing sector and its impact on business-related services: an input-output study for Germany. Structural Change and Economic Dynamics, v. 16, n. 4, p. 467-488, 2005.

FREEMAN, Christopher et al. As time goes by: from the industrial revolutions to the information revolution. Oxford University Press, 2001.

FUCHS, Victor R. et al. The service economy. NBER Books, 1968.

GALLOUJ, F.; WEINSTEIN, O. Innovation in services. Research Policy, v. 26, n. 4, p. 537-556, 1997.

GEREFFI, G.; FREDERICK, S. The global apparel value chain, trade and the crisis: challenges and opportunities for developing countries. World Bank Policy Research Working Paper Series, 2010.

GIOVANINI, Adilson; AREND, Marcelo. Contribution of services to economic growth: Kaldor's fifth law? Revista de Administração Mackenzie, v. 18, n. 4, p. 190-213, 2017.

GUERRIERI, P.; MELICIANI, V. Technology and international competitiveness: the interdependence between manufacturing and producer services. Structural Change and Economic Dynamics, v. 16, n. 4, p. 489-502, 2005.

HERTOG, P. D. Knowledge-intensive business services as co-producers of innovation. International Journal of Innovation Management, v. 4, n. 4, p. 491-528, 2000.

HIDALGO, Cesar A. The structure and dynamics of economic complexity. American Physical Society, APS March Meeting 2011.

HIRSCHMAN, A. O. The strategy of economic growth. Yale, New Haven, 1958. 
KALDOR, N. Causes of the slow rate of economic growth of the United Kingdom: an inaugural lecture. Cambridge University Press, 1966.

KENDRICK, J. W. Measurement of output and productivity in the service sector. Managing the service economy, prospects and problems. 1985. p. 111-133.

KUZNETS, S. Economic growth and income inequality. American Economic Review, v. 45, p. 1-28, 1955.

KUZNETS, S. Quantitative aspects of the economic growth of nations, Part II. Economic Development and Cultural Change, v. 5, n. 4, p. 1-111, 1957.

KUZNETS, S. Modern economic growth: findings and reflections. The American Economic Review, v. 63 , n. 3, p. 247-258, 1973.

LESHER, M.; NORDÅS, H. K. Business services, trade and costs. OCDE Library, 2006.

LEWIS, W. A. Economic development with unlimited supplies of labour. The Manchester School, v. 22, n. 2, p. 139-191, 1954.

LINDEN, G. et al. Who captures value in a global innovation network? the case of Apple's iPod. Communications of the ACM, v. 52, n. 3, p. 140-144, 2009.

MARKUSEN, J. R. Trade in producer services and in other specialised intermediate inputs. American Economic Review, 79, p. 85-95, 1989.

MELICIANI, Valentina et al. Exports of knowledge-intensive services and manufactures: the role of ICTS and intersectoral linkages. Chapters, 2010.

MILES, I. et al. Knowledge intensive business services: their roles as users, carriers and sources of innovation. PREST, Manchester, 1994.

MILES, Ian et al. Knowledge-intensive business services: users, carriers and sources of innovation. European Innovation Monitoring System (EIMS) Reports, 1995.

MILES, I. Patterns of innovation in service industries. IBM Systems Journal, v. 47, n. 1, p. 115-128, 2008.

MIOZZO, M.; SOETE, L. L. G. Internationalisation of services: a technological perspective. In: Third International Conference on Technology Policy and Innovation, Austin, USA, 1999.

MOMIGLIANO, Franco et al. Note in tema di terziarizzazione e deindustrializzazione. Moneta e Credito, v. 35, n. 138, p. 143-182, 1982.

MOMIGLIANO, F.; SINISCALCO, D. Mutamenti nella struttura del sistema produttivo e integrazione fra industria e terziario. Mutamenti Struturali del Sistema Produtivo-integrazione tra industria e settore terziario. Mulino, 1986.

MONTRESOR, Sandro; VITTUCCI MARZETTI, Giuseppe. Outsourcing and structural change. Application to a set of OECD countries. International Review of Applied Economics, v. 24, n. 6, p. 731-752, 2010. 
MONTRESOR, Sandro; VITTUCCI MARZETTI, Giuseppe. The deindustrialisation/tertiarisation hypothesis reconsidered: a subsystem application to the OECD7. Cambridge Journal of Economics, v. 35, n. 2, p. 401-421, 2011.

MULLER, E.; ZENKER, A. Business services as actors of knowledge transformation: the role of KIBS in regional and national innovation systems. Research Policy, v. 30, n. 9, p. 1501-1516, 2001.

NORDÅS, Hildegunn Kyvik. The impact of services trade liberalisation on trade in non-agricultural products. 2008.

NORDÅS, H. K. Trade in goods and services: Two sides of the same coin? Economic Modelling, v. 27, n. 2, p. 496-506, 2010.

NORDÅS, H. K.; KIN, K. Interaction between goods and services trade: case studies. OCDE, Working Party of the Trade Committee. TAD/TC/WP(2013)15, June 4, 2013.

OREIRO, José Luis; FEIJÓ, Carmem A. Desindustrialização: conceituação, causas, efeitos e o caso brasileiro. Brazilian Journal of Political Economy, v. 30, n. 2, p. 219-232, 2010.

ORGANIZAÇÃO PARA A COOPERAÇÃO E DESENVOLVIMENTO ECONÔMICO (OECD). Directorate for science, technology and industry. Stan Indicators, edição 2005, v. 17, 2009.

PALMA, Gabriel et al. Four sources of de-industrialisation and a new concept of the Dutch Disease. Beyond Reforms: Structural Dynamics and Macroeconomic Vulnerability, v. 3, n. 5, p. 71116, 2005.

PARK, S.; CHAN, K. S. A cross-country input-output analysis of intersectoral relationships between manufacturing and services and their employment implications. World Development, v. 17, n. 2, p. $199-212,1989$.

PASINETTI, Luigi Lodovico. The notion of vertical integration in economic analysis. Metroeconomica, 1973.

PEREZ, C. Revoluciones tecnológicas y capital financiero: la dinámica de las grandes burbujas financieras y las épocas de bonanza. México: Siglo XXI, 2004.

RAMPA, G. Commento a Momigliano e Siniscalco. Moneta e Credito, v. 139, p. 475-479, 1982.

RODRIGUE, J. Transportation and the geographical and functional integration of global production networks. Growth and Change, v. 37, n. 4, p. 510-525, 2006.

ROWTHORN, Robert Eric; RAMASWAMY, Ramana. Deindustrialization: causes and implications. International Monetary Fund, 1997.

ROWTHORN, Robert; RAMASWAMY, Ramana. Growth, trade, and deindustrialization. IMF Staff Papers, p. 18-41, 1999.

SARRA, Alessandro; DI BERARDINO, Claudio; QUAGLIONE, Davide. Deindustrialization and the technological intensity of manufacturing subsystems in the European Union. Economia Politica, v. 36, n. 1, p. 205-243, 2019. 
SAVONA, Maria; STEINMUELLER, W. Edward. Service output, innovation and productivity: A time-based conceptual framework. Structural Change and Economic Dynamics, v. 27, p. 118-132, 2013.

SQUEFF, G. C. Desindustrialização: luzes e sombras no debate brasileiro. Brasília, jun. 2012. (Texto para Discussão, n. 1747). Disponível em: http://repositorio.ipea.gov.br/bitstream/11058/1125/1/TD_1747.pdf. Acesso em: 3 maio 2016.

SRAFFA, Piero. Produzione di merci a mezzo di merci: premesse a una critica della teoria economica. G. Einaudi, 1960.

TREGENNA, Fiona. Characterizing deindustrialization: an analysis of changes in manufacturing employment and output internationally. Cambridge Journal of Economics, v. 33, 2009.

TRIPLETT, J. E.; BOSWORTH, B. Productivity measurement issues in services industries: Baumol's disease has been cured. Economic Policy Review, v. 9, n. 3, 2003.

TRIPLETT, J. E.; BOSWORTH, B. Productivity in the US services sector: new sources of economic growth. Brookings Institution Press, 2004.

WINDRUM, P.; TOMLINSON, M. Knowledge-intensive services and international competitiveness: a four country comparison. Technology Analysis \& Strategic Management, v. 11, n. 3, p. 391-408, 1999.

WOOD, A. North-South trade, employment and inequality: changing fortunes in a skill-driven world. Oxford: Clarendon Press, 1994. 


\section{Apêndice}

Apêndice A.1. Participação das horas trabalhadas do ramo de serviços intermediários na demanda final dos subsistemas industriais

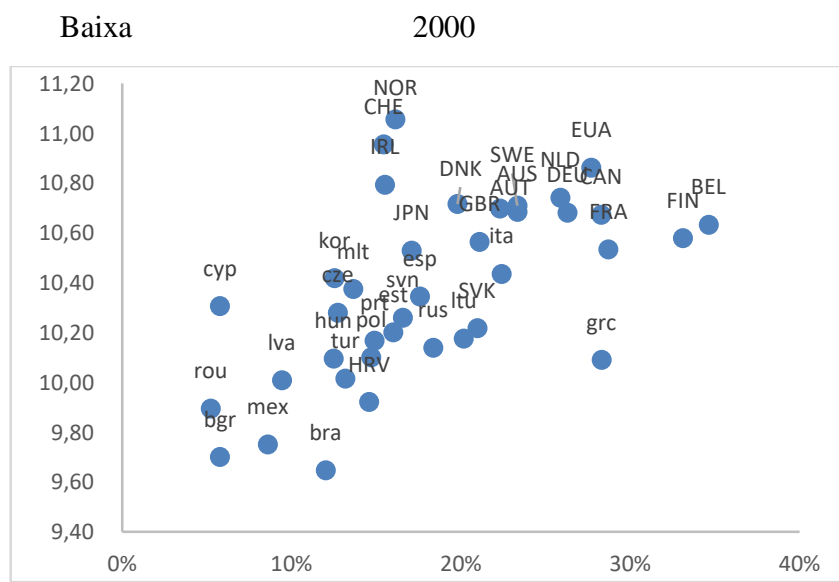

2014

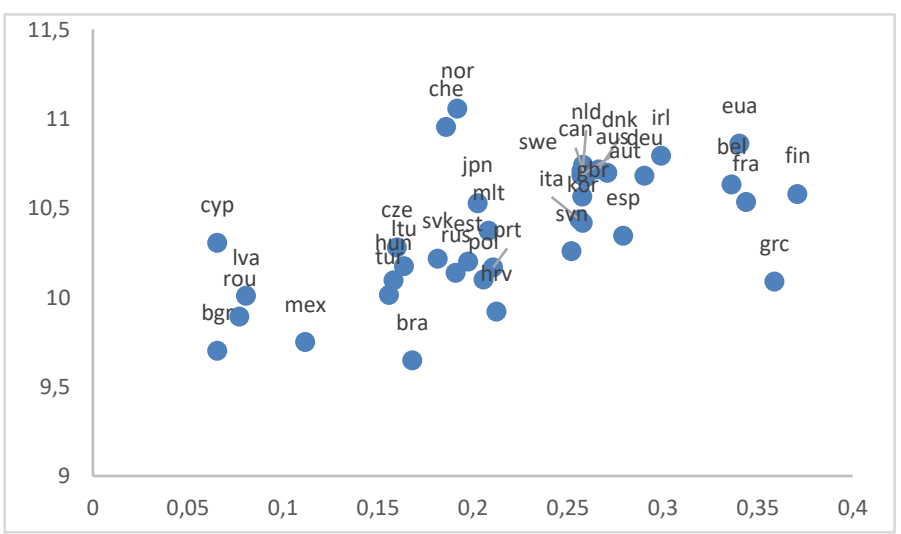

Média-baixa
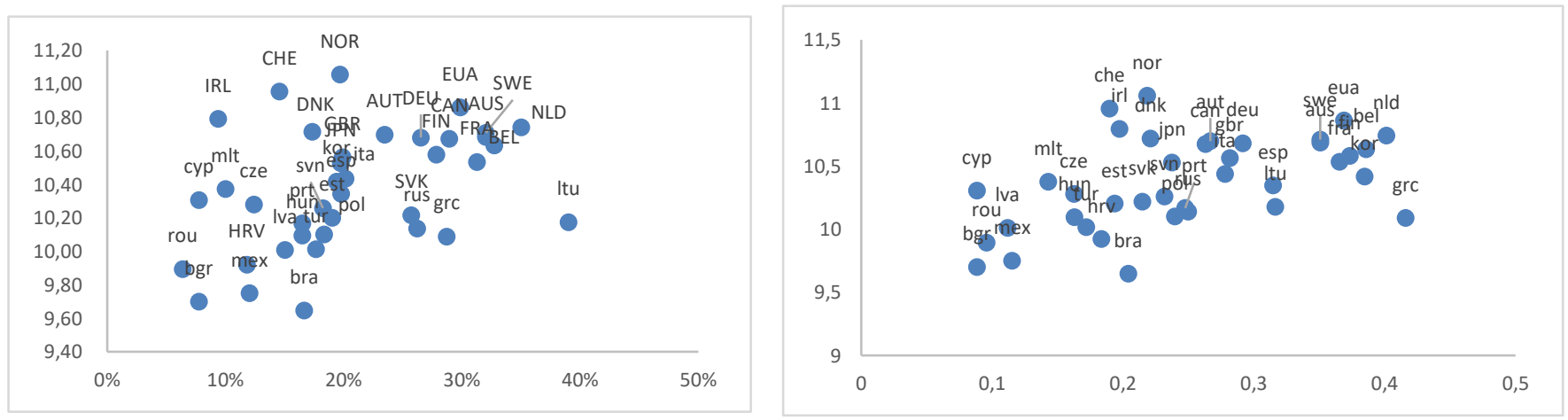
Média-alta
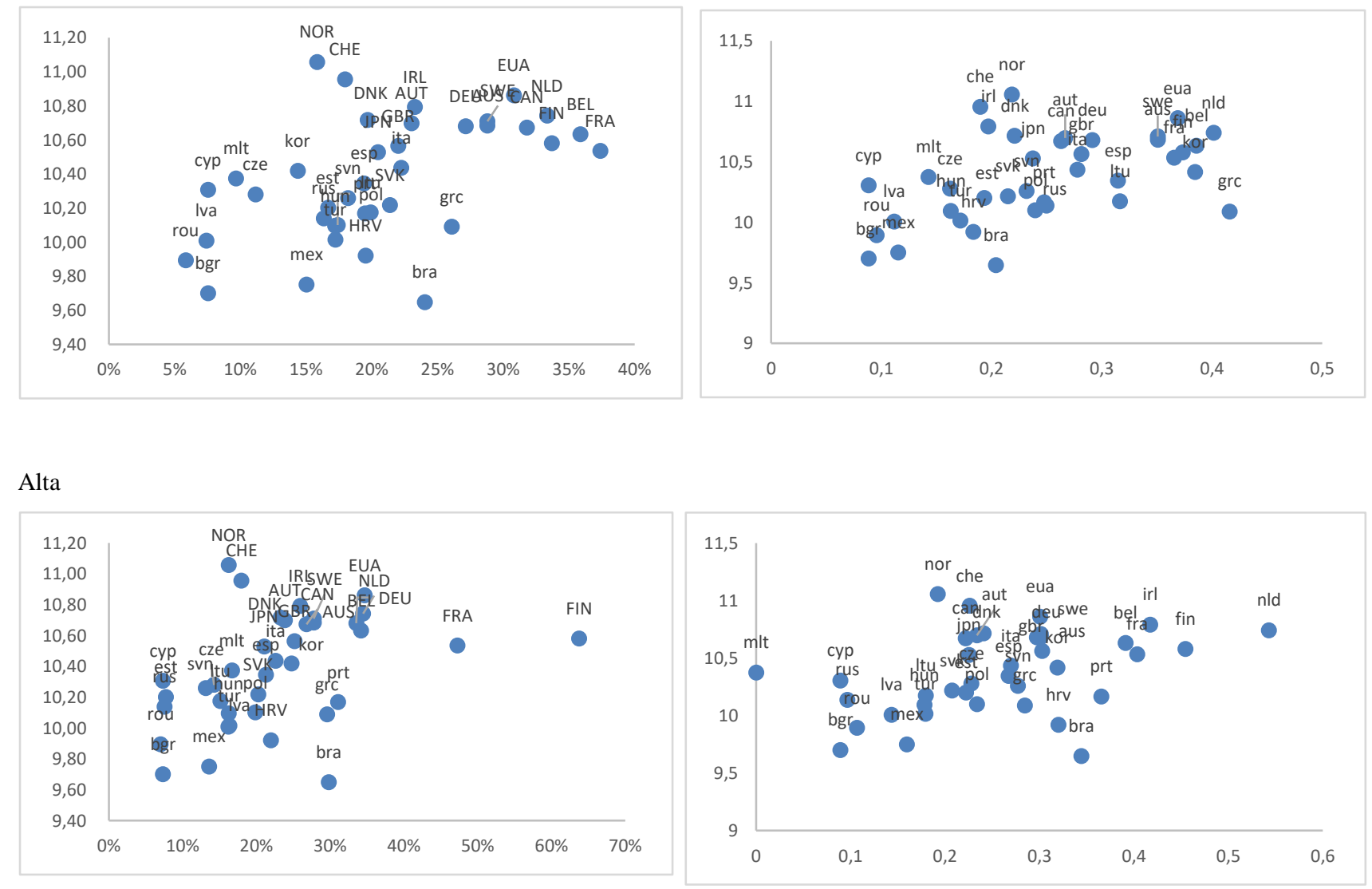

Fonte: Elaboração própria. 
Mudança estrutural e serviços intermediários: algumas evidências para o limiar do século XXI

Apêndice A.2. Taxa de crescimento anualizada da participação nas horas trabalhadas, discriminada de acordo com a intensidade tecnológica dos subsistemas industriais, período 2000-2014

Baixa

$$
\begin{aligned}
& \text { - } 04 \% 3 \%-03 \% 03 \% 03 \% 03 \% 03 \% 03 \% 03 \% 02 \%-2 \%-2 \%-2 \%-2 \%-2 \%-2 \%-2 \%-2 \%-2 \%-2 \%-2 \%-2 \%-2 \%-2 \%-2 \%-2 \%-1 \%-1 \%-1 \%-1 \%-1 \%-1 \%-1 \%-1 \%-1 \%-1 \% 0 \% 0 \%
\end{aligned}
$$

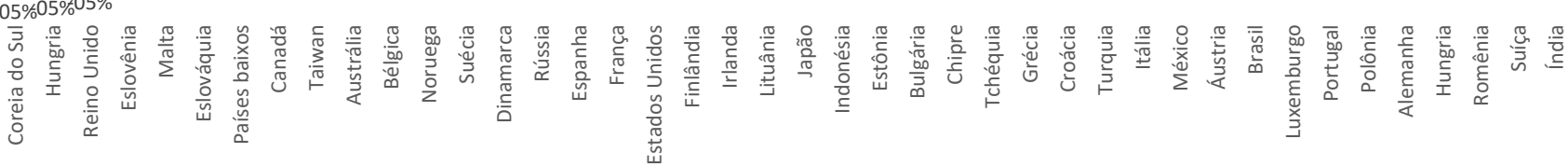

Média-baixa

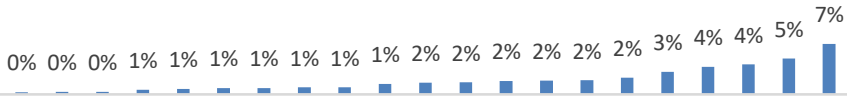

1

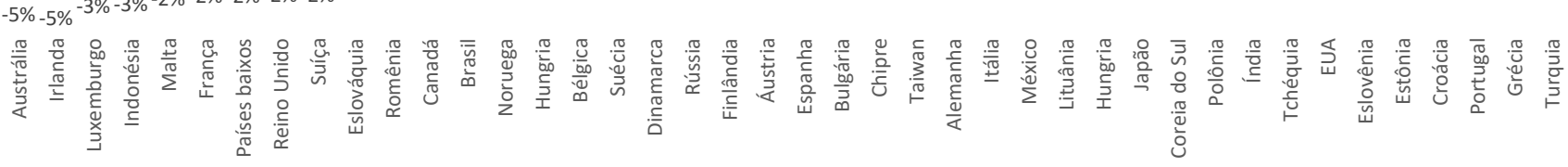

Média-alta

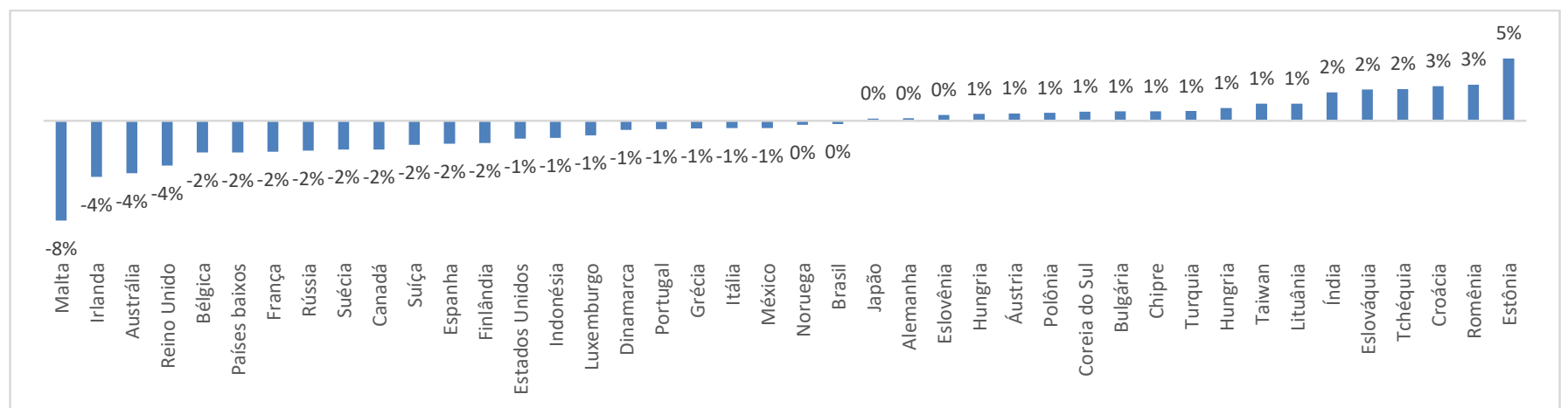


Alta

$0 \% 0 \% 0 \% 2 \% 2 \% 3 \% 3 \% 3 \%$

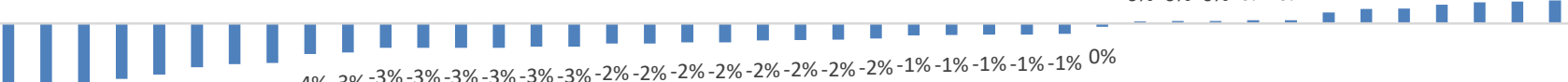

${ }_{-10 \%}^{-7 \%-7 \%-6 \%-5 \%-5 \%-5 \%-4 \%-3 \%-3 \%-3 \%-3 \%-3 \%-3 \%-3 \%-2 \%-2 \%-2 \%-2 \%-2 \%-2 \%-2 \%-2 \%-1 \%-1 \%-1 \%-1 \%-1 \%-0 \%}$

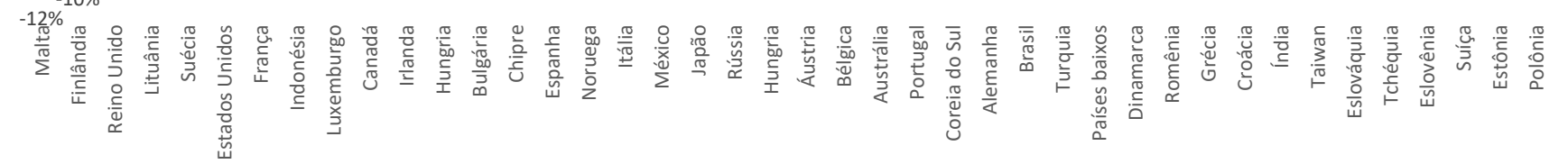

Int.

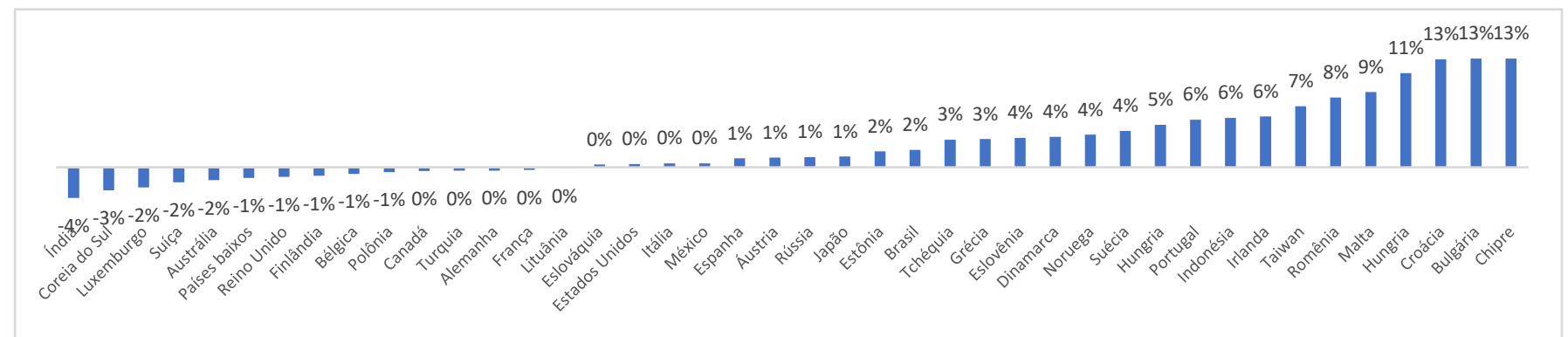

Fonte: Elaboração própria. 